\title{
Current Perspectives of Prenatal Sonography of Umbilical Cord Morphology
}

\author{
David M Sherer (D) \\ Sara Al-Haddad (D) \\ Regina Cheng \\ Mudar Dalloul (D)
}

The Division of Maternal Fetal Medicine, The Department of Obstetrics and Gynecology, State University of New York (SUNY), Downstate Health Sciences University, Brooklyn, NY, USA
Correspondence: David M Sherer Division of Maternal-Fetal Medicine, Department of Obstetrics and

Gynecology, State University of New York (SUNY), Downstate Health Sciences

University, 450 Clarkson Avenue, Box 24, Brooklyn, NY, USA

Tel + I $7 \mid 8$ 270-208|

$\mathrm{Fax}+1718270-4122$

Email davidmsherer@gmail.com

\begin{abstract}
The umbilical cord constitutes a continuation of the fetal cardiovascular system anatomically bridging between the placenta and the fetus. This structure, critical in human development, enables mobility of the developing fetus within the gestational sac in contrast to the placenta, which is anchored to the uterine wall. The umbilical cord is protected by unique, robust anatomical features, which include: length of the umbilical cord, Wharton's jelly, two umbilical arteries, coiling, and suspension in amniotic fluid. These features all contribute to protect and buffer this essential structure from potential detrimental twisting, shearing, torsion, and compression forces throughout gestation, and specifically during labor and delivery. The arterial components of the umbilical cord are further protected by the presence of Hyrtl's anastomosis between the two respective umbilical arteries. Abnormalities of the umbilical cord are uncommon yet include excessively long or short cords, hyper or hypocoiling, cysts, single umbilical artery, supernumerary vessels, rarely an absent umbilical cord, stricture, furcate and velamentous insertions (including vasa previa), umbilical vein and arterial thrombosis, umbilical artery aneurysm, hematomas, and tumors (including hemangioma angiomyxoma and teratoma). This commentary will address current perspectives of prenatal sonography of the umbilical cord, including structural anomalies and the potential impact of future imaging technologies.
\end{abstract}

Keywords: prenatal ultrasound, umbilical cord, color Doppler imaging

\section{Introduction}

The umbilical cord is a direct continuation of the fetal cardiovascular system. Anatomically bridging between the placenta and the fetus, this structure critical in human development enables mobility of the developing fetus in contrast to the placenta, which is anchored to the uterine wall. The umbilical cord assures a flexible delivery system of both oxygen and nutrients with concurrent removal of carbon dioxide and other waste components/elements towards the placenta and away from the tethered fetus while concurrently enabling the fetus to develop in an almost unrestricted aquatic environment facilitating pulmonary and joint extension/ flexion development. It is interesting to compare this robust life-support system to the system devised initially by the National Aeronautics and Space Administration (NASA) to sustain human life during the first extra vehicular activity (EVA) in space, which clearly appears to have mimicked nature in this aspect (Figure 1).

The umbilical cord develops from the yolk sac and allantois. At 18 days postconception, a duct-like extension of the yolk sac from the future caudal region of the embryo develops into the connecting stalk - The transitory allantois. ${ }^{1}$ On postconception day 22, the allantois and extra-embryonic yolk sac extend into the 


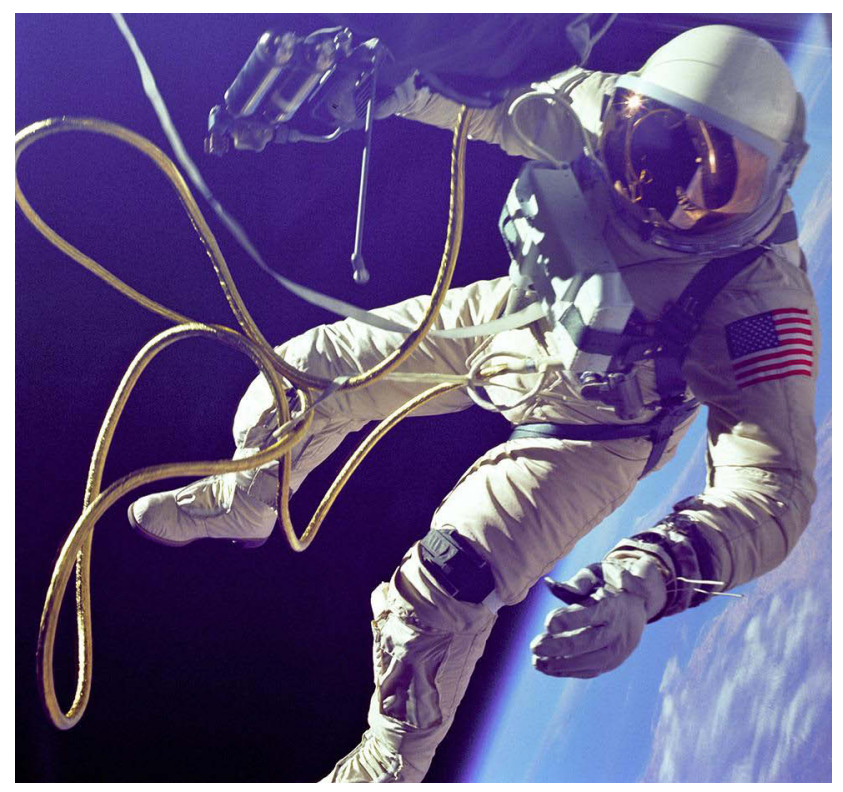

Figure I The first USA Extra Vehicular Activity (EVA) June 3, 1965, Edward White, (Astronauts Edward White and James McDivitt, Gemini 4, NASA). During the 21 minute long spacewalk, Ed White was tethered to the Gemini spacecraft by a 25 foot "umbilical cord" through which oxygen was supplied. The tethering cord also carried communications and biomedical instrumentation. Note the fine mesh surrounding the cord enhancing flexibility and strength and overall the striking similarity of the supply cord to the human umbilical cord. Interestingly, similar to the umbilical cord the NASA system is tethered to the mid-torso (left mid abdomen) of the astronaut.

Notes: NASA image. This figure was reproduced from: Wikipedia. Ed White, the first American to perform extravehicular activity, outside of Gemini IV; 1965. Available from: https://en.wikipedia.org/wiki/Gemini_4\#/media/File:Ed_White_ First_American_Spacewalker_-_GPN-2000-001180.jpg. Accessed October I, $2021 .^{283}$

mesenchyme of the connecting stalk. Between days 28 and 40 the expanding amniotic cavity compresses the allantois and yolk sac into a cord covered by amnion, creating the umbilical cord. ${ }^{1}$

The umbilical cord lengthens with gradual backward prolapse of the embryo into the amniotic sac. Two allantoic arteries (originating from the internal iliac arteries) and one allantoic vein (entering the hepatic vein) penetrate the placenta and connect with the villous vessels during the third post-conception week. During the second month of pregnancy, the originally developed second umbilical vein undergoes atrophy. ${ }^{1}$ Wharton's jelly, the subamniotic connective tissue of the umbilical cord, is derived from extraembryonic mesoblast contributing the mucoid, which provides the compressible property of the umbilical cord. Gradual lengthening of the umbilical cord during the first trimester is accompanied by coiling. The mean length of the umbilical cord is approximately $55 \mathrm{~cm}$, with measurements above $80 \mathrm{~cm}$ and below 35-40 cm, considered excessively long and short, respectively. While excessively long umbilical cords have been associated with increased coiling, increased risk of entanglement and knotting, short umbilical cords have been associated with an increased risk of adverse perinatal outcome, intrapartum fetal heart rate abnormalities, and increased likelihood of placental abruption and postpartum hemorrhage. ${ }^{1}$

In this fashion, Wharton's jelly, two umbilical arteries, coiling, suspension in amniotic fluid and the length of the umbilical cord, protect and buffer the umbilical cord from twisting, shearing, torsion and compression forces throughout gestation, and specifically during fetal descent during labor. Reflecting the inherent strength of this vital structure, the average tensile breaking load of the umbilical cord has been reported at 2.49 times birth weight. ${ }^{1}$

An additional safety mechanism of the umbilical cord is Hyrtl's anastomosis. This $1.5-2 \mathrm{~cm}$ shunt between the umbilical arteries is positioned within $3 \mathrm{~cm}$ of the placental cord insertion. This intra-arterial anastomosis, which is present in approximately $96 \%$ of umbilical cords, equalizes pressures between the two respective umbilical arteries before entering the placenta and functions as a safety valve in the event of placental compression or umbilical artery blockage. ${ }^{1}$ Prenatal sonography of the Hyrtl anastomosis will be discussed in detail following. ${ }^{2,3}$

Recent emerging data support that approximately 20\% of stillbirth cases can be attributed at autopsy to lethal compromise of umbilical cord circulation. ${ }^{4-6}$ Furthermore, precise placental histological criteria accompanying restriction of umbilical cord flow have been established, which enable unique determination of potential umbilical cord compromise, previously unsuspected prior to histological assessment. ${ }^{7,8}$ An additional intriguing observation of umbilical cord lesions noted in association with early intrauterine fetal demise was forwarded in 2003 by Singh et al. ${ }^{9}$ These authors assessed products of conception of 122 (of a total of 153) cases of fetal demise $<16$ weeks' gestation, in which medical evacuation of the uterus yielded intact products of conception (the 31 remaining cases underwent surgical uterine evacuation), noting that in $13 / 122(10.7 \%)$ of these cases demonstrated abnormalities of the umbilical cord. Umbilical cord lesions encountered most commonly, were constriction and coiling abnormalities, while others consisted of hemorrhage, thrombosis, edema, and amniotic bands.

A considerable array of structural umbilical cord abnormalities exists including: excessively long or short cords, hyper or hypocoiling, cysts, single umbilical artery, supernumerary vessels, rarely an absent umbilical cord, 
stricture(s), furcate and velamentous insertions (including vasa previa), umbilical vein and arterial thromboses, umbilical artery aneurysm, hematomas and tumors (including hemangioma angiomyxoma and teratoma). ${ }^{1,9,10}$

During the quarter century, which has elapsed since we last assessed the challenges encountered in ultrasonographic assessment of the umbilical cord, advanced technologies including color and Power Doppler imaging and three-dimensional sonography have become widespread and enabled enhanced imaging of this somewhat "evasive" anatomical structure. ${ }^{10,11}$ This commentary addresses current perspectives of prenatal sonography of the umbilical cord in singleton and multiple gestations. Various manifestations of umbilical cord entanglement, namely nuchal cord(s), true $\operatorname{knot}(\mathrm{s})$, and complex entanglement of the umbilical cord, have been presented in detail in earlier separately published commentaries in the Journal, and hence, although involving the umbilical cord per se, various manifestations of umbilical cord entanglement and arterial or venous Doppler assessments will not be addressed in this commentary. ${ }^{12-14}$

\section{Umbilical Cord Morphometry Length}

As mentioned, the length of the umbilical cord is critical in promoting almost unlimited, free fetal movement. The average umbilical cord length is approximately 55-60 cm in length. ${ }^{15-17}$ While various nomograms have been established for each gestational week (with short and long umbilical cords being defined as $<10$ th and $>90$ th centiles for gestational age, respectively), in general at term, short umbilical cords are considered those measuring $<40 \mathrm{~cm}$, while the definition of an excessively long umbilical cord has been reported as $>80$ or $100 \mathrm{~cm}$, although umbilical cords as long as 165 or even $300 \mathrm{~cm}$ have been reported. ${ }^{1}$ Both excessively long and short umbilical cords, respectively, have been associated with an increase in adverse perinatal outcome. ${ }^{1,17}$ Berg and Rayburn in a study of 3109 consecutive singleton pregnancies finding [(61 cases $(2 \%)$ of short cords $(13-35 \mathrm{~cm}))$, and (112 cases $(3.7 \%)$ of cases of long cords $(80-121 \mathrm{~cm}))]$ noted that umbilical blood $\mathrm{pH}$ and base excess values were similar in pregnancies with short $(7.35 \pm 0.90$, and $3.1 \pm 2.7 \mathrm{mEq} / \mathrm{L}$ mean $\pm \mathrm{SD})$, normal length $(7.36 \pm 0.03$ and $3.8 \pm 1.7$ $\mathrm{mEq} / \mathrm{L})$ and long $(7.34 \pm 0.06$ and $3.7 \pm 3.1 \mathrm{mEq} / \mathrm{L})$ umbilical cords. $^{18}$
Excessively long umbilical cords clearly predispose to cord entanglement [true $\operatorname{knot}(\mathrm{s})$, nuchal cord(s) and other complex entanglements]. For detailed prenatal sonographic assessments and suggested management regarding each of these separate entities, the reader is referred to three recently published Commentaries in the Journal. ${ }^{12-14}$ An interesting observation is the direct association between the length of umbilical cord and degree (number of nuchal cord loops, true knots and coverall complex umbilical cord entanglement). Also of interest is the possible association of an increased risk of fetal growth restriction associated with excessively long umbilical cords, ${ }^{19,20}$ and reported fetal thrombotic vasculopathy, which has been reported to predispose the placenta to marked fetal thrombotic vasculopathy. ${ }^{21}$

The underlying etiology of excessively long umbilical cords is unclear, yet excessive fetal movements early in gestation have been considered as a possible etiology of this occurrence.

In contrast, excessively short umbilical cords are less common, and often are associated with fetal anomalies, including: Pena Shokeir sequence (fetal hypokinesia/akinesia sequence), ${ }^{22,23}$ Neu Laxova syndrome, ${ }^{24}$ other rare constrictive dermopathies, ${ }^{25,26}$ and arthrogryposis. ${ }^{27}$ Interestingly, all of these conditions are associated with decreased or absent fetal movement, further strengthening the association between fetal movement and overall umbilical cord length. Additional fetal anomalies associated with short umbilical cords include: limb-body wall complex (or body stalk anomaly), ${ }^{28-37}$ and ectopia cordis, ${ }^{38}$ with both the latter groups representing lethal fetal anomalies and the former considered a result of either spontaneous early amnion disruption, vascular disruption, or embryonic dysgenesis. ${ }^{28}$

Short umbilical cords $(<40 \mathrm{~cm})$ in the absence of associated fetal anomalies have been associated with a significant increase in Cesarean and operative vaginal births (both forceps and vacuum deliveries). ${ }^{39}$ Short umbilical cords have also been associated with an increased likelihood of placental abruption, ${ }^{40,41}$ uterine inversion and the associated potential massive postpartum hemorrhage. ${ }^{42}$

In addition, short umbilical cords have been associated with decreased intelligence quotas (IQ). Interestingly, a recent study reported that umbilical cord length affects the efficacy of amnioinfusion for repetitive variable decelerations during labor. ${ }^{43}$ Specifically, these authors reported that short umbilical cord length (lower Z-score) was related to emergency Cesarean delivery after failed therapeutic amnioinfusion for repetitive variable decelerations. ${ }^{43}$ 
Yamamoto et al in 2017 attempted to determine the umbilical cord lengths associated with the strongest correlation with adverse pregnancy outcomes [including the rate of Cesarean delivery, frequency of operative vaginal delivery, small-for-gestational-age (SGA) births, neonatal intensive care unit (NICU) admission, umbilical artery $\mathrm{pH}<7.1$ and abnormal intrapartum hemorrhage]. ${ }^{44}$ These authors in a retrospective fashion determined that umbilical cord lengths of 35 and $45 \mathrm{~cm}$ corresponded to the first and tenth percentiles, respectively, and established that an umbilical cord length of $\leq 45 \mathrm{~cm}$ is a clinically useful indicator of adverse pregnancy outcomes. ${ }^{44}$

Rare cases of absent umbilical cord - achordia - have been reported and are usually associated with structural fetal anomalies including abdominal wall defects, limb body wall sequence. $^{36,45,46}$ Other rare cases of absent umbilical cord have been reported, such as the recent publication of prenatal sonographic confirmation of the recipient twin in a case of twin reversed arterial perfusion (TRAP) sequence, which was completely embedded in the placenta with no evidence of an umbilical cord at delivery (Figure 2). ${ }^{47}$

In contrast to other fetal organs, the placenta or the uterine cervix, the umbilical cord is seldom depicted or tracked sonographically throughout its entire length. This reflects a number of reasons. In general, difficulty (not surprisingly) is encountered tracking a longitudinal



Figure 2 Absent umbilical cord in a (twin reverse arterial perfusion TRAP) twin embedded within the placenta. Note the absence of an umbilical cord to this fetus. Notes: Reproduced with permission from: Sherer DM, Dalloul M, Garza M, Benton L, Abulafia O. Prenatal sonographic diagnosis of acardiac twin embedded within the placenta. Ultrasound Obstet Gynecol. 2018;52(I):120-121. ${ }^{47}$ Copyright () 2017 ISUOG. Published by John Wiley \& Sons Ltd. essentially two-dimensional free-floating structure, within a three-dimensional volume (the gestational sac). In addition, the fetus (especially in the late second and third trimesters) often obscures considerable segments of the umbilical cord, which are thus inaccessible to sonographic interrogation.

Sonographic depiction of the entire umbilical cord has rarely been reported. These reports have mainly been limited either to the first-trimester of pregnancy, or of rare cases involving markedly shortened umbilical cord length. ${ }^{48-50}$

Ugurlucan and Yuksel suggest that sonographically tracing the entire length of the umbilical cord "from the fetal insertion site to the placental insertion" is feasible, with only one unsuccessful case $(0.2 \%)$ during the secondtrimester, an observation, which regretfully, is not our experience and to our knowledge has not been replicated. $^{51}$

Recently, in an unconfirmed report, Gur et al investigated whether Doppler resistance indices obtained at different points of the umbilical cord (fetal and placental insertions, free loop, and intra-abdominal portion between 37 and 42 weeks' gestation in low-risk, singleton pregnancies, are related to umbilical cord length (measured after delivery)). ${ }^{52}$ The study included 74 participants. The mean umbilical cord length was $58 \mathrm{~cm}$. Umbilical artery systolic diastolic ratio (S/D) resistance index (RI) and pulsatility index (PI) were higher in the intra-abdominal portion than other measurement points $(\mathrm{P}=0.03,<001,<0.001$, respectively). The mean differences (delta values) of umbilical artery flow velocities between the fetal and placental insertion points correlated with umbilical cord length $(\mathrm{c}=0.32$, $\mathrm{P}=0.4$ ), suggesting that the differences in umbilical flow velocities at the distal points of the umbilical cord (fetal and placental insertions) may be a useful, although indirect, marker for the prediction of umbilical cord length. ${ }^{52}$ It is interesting to note that the authors did not forward information regarding nuchal cord(s) or true knot(s) of the umbilical cord, the presence of either (or both simultaneously) which, in our assessment (the tightness of which), may also affect Doppler resistance indices. ${ }^{52}$

Increasing utilization of Color Doppler, Power Doppler, and 3D ultrasound in concert with other imaging diagnostic tools enhance depiction of abnormalities of the umbilical cord. Furthermore, it appears likely that depiction of the entire length of the umbilical cord may be within reach in the future with increasing application of new emerging imaging technologies, for example, (CT 
and/or MR imaging and 3D computer-assisted reconstruction techniques), which may enable depiction of the umbilical cord positioned behind the fetal body, inaccessible to transabdominal sonography. ${ }^{53}$ In any event, although governing body guidelines currently suffice with the directive that prenatal sonographic assessments should include depiction of the fetal and placental insertion points of the umbilical cord, we believe that all visible portions of the umbilical cord should be assessed in order to potentially depict abnormalities of this organ critical in human development.

\section{Cross-Section (Diameter)}

Ghezzi et al in 2001, assessing first-trimester sonographic umbilical cord diameter and growth of the human embryo, noted that the umbilical cord diameter increased gradually between 8 and 15 weeks' gestation. ${ }^{54}$ Umbilical cord diameter and gestational age correlated significantly $(\mathrm{r}=0.78 ; \mathrm{P}<0.001)$, umbilical cord diameter and crownrump length $(\mathrm{r}=0.75 ; \mathrm{P}<0.001)$, and umbilical cord diameter and biparietal diameter $(\mathrm{r}=0.81 ; \mathrm{P}<0.001)$. No correlation was noted between umbilical cord diameter and birth weight or placental weight at delivery. Among patients who had a miscarriage $(n=7)$ and pre-eclampsia $(\mathrm{n}=8)$, the umbilical cord diameter was two SD below the mean in three cases $(42.9 \%)$ and three cases $(37.5 \%)$, respectively. 54

Interestingly, this same group of investigators noted that among 784 patients undergoing routine sonographic evaluation between 10 and 14 weeks' gestation, the number of fetuses with an umbilical cord diameter above the 95th centile for gestational age was higher in the presence of fetal or placental chromosomal abnormalities than in normal fetuses $(5 / 17$ vs $39 / 767, \mathrm{P}<0.01){ }^{55}$ Thus, firsttrimester sonographic umbilical cord morphology (diameter) was considered to identify a subset of fetuses at increased risk of fetal chromosomal abnormalities, a finding confirmed by a later study by Axt-Fliedner et al. ${ }^{56}$

Weissman et al in 1994 established nomograms of the umbilical cord and umbilical vessels throughout gestation. The remainder of these data will be described following under the heading "Wharton's Jelly". 57

\section{Wharton's Jelly}

Wharton's jelly, the connective tissue of the umbilical cord, is derived from the extraembryonic mesoblast. ${ }^{1}$ This structure that surrounds and encompasses the umbilical vessels is composed of a ground substance of open-chain polysaccharides (hyaluronic acid, carbohydrates with glycosyl and mannosyl groups), which comprise a fine network of microfibrils dispersed in small amounts of collagen. ${ }^{1}$ This content of Wharton's jelly yields a relatively firm structure, which enables contraction and distention of the umbilical cord vasculature. Overall, Wharton's jelly protects the umbilical cord vessels from external physical forces, which, otherwise, may potentially compromise their integrity. ${ }^{58}$

Ghezzi et al in 2001, in an assessment of sonographic cross-section area of the umbilical cord, and subtracting the vascular area from the overall umbilical cord area throughout gestation established a nomogram of the sonographic assessment of Wharton's jelly in 659 fetuses between 15 and 42 weeks' gestation. ${ }^{59}$ This study established that the Wharton's jelly area increases with advancing gestational age and correlates with fetal size up to 32 weeks' gestation. ${ }^{59}$

In later studies, these investigators reported that prenatal sonographic depiction of a lean umbilical cord may serve as a simple identifier of fetuses destined to small-forgestational age (SGA) birth weight. ${ }^{60}$ The number of subsequent SGA neonates at birth, exhibiting a lean umbilical cord was higher than those with normal umbilical cord biometry parameters $(11.5 \%$ vs $2.6 \%, \mathrm{P}<0.05)$, and fetuses exhibiting a lean umbilical cord exhibited a 4.4-fold increased risk of being SGA at delivery than those with normal umbilical cord biometry. ${ }^{60}$ Of note, the incidence of meconium was higher among fetuses with a lean umbilical cord in contrast with those with a normal umbilical cord $(14.6 \%$ vs $3.1 \% \mathrm{P}<0.001)$. The number of infants with a 5-minute Apgar score $<7$ was considerably higher among those with a lean umbilical cord than among those with normal umbilical cord biometry parameters $(5.2 \%$ vs $1.3 \%, \mathrm{P}<0.05)$. In addition, considering only patients with intact membranes admitted in spontaneous labor with intact membranes who delivered an appropriate for gestational age (AGA) neonate, the proportion of fetuses with oligohydramnios at delivery was higher among those who has lean umbilical cord than among those with normal umbilical cord biometry $(17.6 \%$ versus $1.3 \%, \mathrm{P}<0.01) .^{60}$

These investigators in 2003 compared 84 growthrestricted fetuses (FGR) with 168 (AGA fetuses, noting that the prevalence of lean umbilical cords (cross-sectional area $<10$ th centile for gestational age) was significantly higher among FGR fetuses versus AGA fetuses (73.8\% vs 
$11.3 \% ; \mathrm{P}<0.001)) .{ }^{61}$ In contrast, Cromi et al in a study of 1026 consecutive patients $>34$ weeks' gestation assessed 53 and 22 newborns (5.3\% and $2.1 \%)$ with birth weights $>4000$, and 4500 grams, respectively, noting that the proportion of cases with a large umbilical cord (umbilical cord area $>95$ th centile for gestational age) was significantly higher in the group of macrosomic compared with non-macrosomic infants $(54 \%$ versus $8.7 \%, \mathrm{P}<0.0001){ }^{62}$ Of note, the proportion of umbilical cords with a Wharton's jelly area $>95$ th centile for gestational age was significantly higher among macrosomic fetuses of patients with diabetes versus those without diabetes. In addition, the combination of abdominal circumference $>95$ th centile and large cord predicted $100 \%$ of macrosomic infants. These authors concluded that sonographic assessment of umbilical cord area may improve detection of macrosomia. ${ }^{62}$

Raio et al in 1999 reported that a decrease in Wharton's jelly often occurs in cases of a single umbilical artery, possibly an additional risk factor for fetuses with nuchal cord (see above). ${ }^{63}$ This group of investigators considered that the association of adverse perinatal outcome noted in cases of single umbilical artery (even in the absence of congenital or chromosomal abnormalities) likely reflects the decreased amount of Wharton's jelly. ${ }^{63}$ Thus, the combination of a single umbilical artery and decreased amount of Wharton's jelly may represent a combined compromise of teleological protective mechanisms of the umbilical cord, resulting in increased adverse perinatal outcome of fetuses further complicated by the presence of nuchal cords, and especially multiple nuchal cords. ${ }^{63,64}$

Debebe et al in 2019 correlated prenatal ultrasound images of the umbilical cord with post-delivery pathology assessments of fixed cross-sections of the umbilical cord and placenta. $^{58}$ These authors reported that decreased Wharton's jelly is associated with clinically significant placental pathology and Wharton's jelly area scales proportionally with placental size. ${ }^{58}$ These findings support the concept that Wharton's jelly area as depicted by prenatal ultrasound correlates with the functional capacity of the placenta and thus merits further evaluation with currently available tests of placental function in clinical practice.

Cromi et al in 2005 studied 21 consecutive twins with twin-twin transfusion syndrome and demonstrated that the cross-sections of the umbilical cords of the recipient twins were larger than those of donor twins. ${ }^{65}$ The difference was attributed to both the larger amount of Wharton's jelly and a larger umbilical vein diameter. The proportion of lean umbilical cords was higher in the donor versus recipient twins $(18 / 21$ vs $1 / 21, \mathrm{P}<0.0001)$, while larger umbilical cords were significantly more frequent among recipients versus donor twins $(13 / 21$ vs $1 / 21, \quad \mathrm{P}=$ $0.0002){ }^{65}$

\section{Hyrtl's Anastomosis}

As mentioned earlier, this under-recognized arterial anastomosis is found in approximately $96 \%$ of umbilical cords, and has been considered to equalize umbilical artery pressures prior to insertion in the placenta. ${ }^{1}$

Utilizing angiography, Ullberg et al in 2001, assessed the variable anatomy of the anastomosis between the umbilical arteries in 67 umbilical cords and placentas of full-term appropriate-for-gestational age (AGA) infants. ${ }^{66}$ The angiography methodology enabled calculation of the relative placental area supplied by each umbilical artery. A single anastomosis was noted in 60 cases, two anastomoses in one case, and in four cases the anastomosis was absent, two cases had a single umbilical artery. In cases in which the diameter of the anastomosis at least equaled that of the umbilical arteries, they supplied a mean $26 \%$ and $74 \%( \pm 8.2 \%)$ of the placenta areas, respectively. In cases in which the diameter of the anastomosis was smaller than that of the umbilical artery, they supplied mean placental areas of $41 \%$ and $59 \%( \pm$ $6.0 \%$ ), respectively. Interestingly, in placentas lacking a Hyrtl's anastomosis the two umbilical arteries supplied $45 \%$ and $55 \% \quad( \pm 2.6 \%)$, respectively, indicating a relatively high degree of symmetry. ${ }^{66}$ These authors later in 2003 studied the arterial systems of 64 placentas from singleton pregnancies of small-for-gestational age (SGA) fetuses, comparing these with the previously reported above-data representing AGA infants. ${ }^{67}$ In 56/ 64 placentas, the anastomosis was represented by a true vessel, in two placentas, by a "fenestration" and in two other cases, by fusion of the umbilical arteries. Hyrtl's anastomosis was absent in one case, and in three cases, a single umbilical artery was noted. These authors noted that the overall anatomy of the anastomosis and the relationship between its width and the symmetry between the placental supply areas of each umbilical artery did not differ between placentas from SGA vs AGA infants despite various types of cord insertion and placentation, concluding that static measurements of Hyrtl's anastomosis do not substantiate a contributing factor in fetal growth restriction. ${ }^{67}$ 
Gordon et al developed a computational model for quantitative analysis of hemodynamic characteristic Hyrtl's anastomosis in cases of blood flow discordance in the umbilical arteries. ${ }^{68}$ These authors found that when placental territories of one umbilical artery force increased resistance to fetal blood flow -Hyrtl's anastomosis redistributes blood in the second umbilical artery, reducing the high-pressure gradients in the affected artery. ${ }^{68}$ Conversely, when one of the umbilical arteries conducts a smaller blood flow into the placenta and a relatively smaller pressure is developed, Hyrtl's anastomosis rebuilds the pressure gradient in the affected umbilical artery, redistributing blood flow and improving placental perfusion. ${ }^{67}$

Raio et al in 1999 reported two cases of in utero depiction of blood flow within Hyrtl's anastomosis with a pulsatile blood flow from the umbilical artery with a higher resistance index to the umbilical artery with a lower resistance index. ${ }^{2}$ This finding was confirmed after delivery, supporting the hypothesis that Hyrtl's anastomosis functions in equalizing blood pressure between the two umbilical arteries and regulating blood pressure within the placental lobes. ${ }^{2}$ This same group of investigators in 2001 reported a series of functional evaluations of Hyrtl's anastomosis in 41 women, measuring the resistance index of the anastomosis and the umbilical arteries proximal and distal to the anastomosis. ${ }^{3}$ The direction of blood flow within the anastomosis was depicted by color Doppler imaging. An anastomosis between the two stems of the umbilical arteries was present in 36/41 cases, and fusion of the two umbilical arteries was noted in the remaining five cases. $^{3}$ The mean diameter of the anastomosis was $2.3 \mathrm{~mm}(1.3-7.1)$, and the pulsatile blood flow within the anastomosis exhibited a mean resistance index of $0.62(0.45-0.85)$ and was unidirectional towards the umbilical artery with a lower resistance index. The difference between the resistance indices of the two umbilical arteries was noted to be higher distal, rather than proximal to the anastomosis $[0.07(0-0.30)$ versus $0.04(0-0.17), \mathrm{P}=0.05]$. The median diameter of Hyrtl's anastomosis was considerably higher when the anastomosis was oblique $(\mathrm{n}=8)$ than when it was transverse $(\mathrm{n}=28)$ [4.8 $\mathrm{mm}(2-7.1)$ versus $2.3 \mathrm{~mm}(1.3-1.5), \mathrm{P}<$ $0.05]$. Interestingly, in three of the five cases with fused umbilical arteries, the umbilical cord placental insertion was marginal or velamentous. These data were considered to substantiate the hypothesis that this unique anastomosis functions as a "pressure - equalizing" mechanism between the two umbilical arteries, which is likely of clinical importance when the areas within the placenta supplied by the umbilical arteries differ in size. $^{3}$

Bhutia et al in 2014 assessed umbilical cords and placentas of 100 normotensive patients versus those of 100 patients with "pregnancy-induced" hypertension. ${ }^{69}$ A single anastomosis was observed in 167 specimens, the umbilical arteries were fused in 16 cases, there was no anastomosis in 15 cases, and there was a single umbilical artery in two cases. A double anastomosis was noted in one case of a patient with hypertension. ${ }^{69}$ Overall, these authors reported that the morphology of Hyrtl's anastomosis considerably differed between normotensive versus hypertensive patients. The incidence of a transverse versus an oblique anastomosis was higher, the length of the anastomosis and its distance from the umbilical cord insertion were shorter among specimens of hypertensive compared with normotensive patients. The significance of these findings (if any) is unclear. ${ }^{69}$

Donepudi et al recently reported a recent interesting case of repeated intrauterine transfusions (between 19 and 35 weeks' gestation) complicated by umbilical artery thrombosis following the fifth intrauterine transfusion. ${ }^{70}$ Further transfusions were uneventful, and delivery at term of an uncompromised infant was reported. The authors propose that although the complication of umbilical artery thrombosis is unusual and optimal management is unclear, the presence of Hyrtl's anastomosis may explain the reassuring fetal status throughout the pregnancy despite the post-transfusion umbilical artery thrombosis. ${ }^{70}$

Thus, it is apparent that Hyrtl's anastomosis may play a formidable function, especially in the context of compensatory prevention of potential fetal compromise due to vascular/placental insufficiency. Notwithstanding, prenatal sonographic depiction of Hyrtl's anastomosis is not currently applied and remains an investigational tool.

\section{Number of Umbilical Vessels}

Following spontaneous atrophy of the second umbilical vein throughout the second month of pregnancy, the normal umbilical cord contains a single umbilical vein directing oxygenated blood towards the fetus and subsequently through the ductus venosus - bypassing the fetal liver directing the high-velocity oxygenated blood preferentially towards and across the foramen ovale to the left side of the fetal heart, to the brain, heart and adrenals, thus bypassing 
the right side of the fetal heart, and two umbilical arteries emanating from the fetal hypogastric arteries. ${ }^{1}$

\section{Single Umbilical Artery}

Single umbilical artery is the most common structural anomaly of humans, with a noted incidence of between $0.63 \%$ and $1 \%$ of newborns. ${ }^{1}$ Rembouskos et al determined a possible association between a single umbilical artery (SUA) at 11-14 weeks of gestation and the incidence of chromosomal abnormalities. ${ }^{71}$ Utilizing color Doppler imaging of the fetal pelvis, these authors determined the number of umbilical arteries in 717 fetuses immediately before chorionic villus sampling for karyotyping at 11-14 weeks' gestation. These authors noted the presence of a single umbilical artery (SUA) in 21/634 (3.3\%) euploid fetuses, in 5/44 (11.4\%) fetuses with Trisomy 21, 14/18 (77.8\%) fetuses with Trisomy 18 and $2 / 21(9.5 \%)$ with a variety of chromosomal abnormalities. No significant differences in median fetal crown-rump length or nuchal translucency (NT) between those with a single and those with two umbilical arteries in the chromosomally normal group were noted. Among 42 fetuses with SUA, the expected number of cases of Trisomy 21, estimated according to maternal age, gestational age and fetal NT, was 4.7, not significantly different from the observed 5. Corresponding numbers for Trisomy 18 were 2.0 for expected and 14 for observed (Fisher's exact test $\mathrm{P}=0.0016$ ). Thus, these authors concluded that a SUA at 11-14 weeks' gestation has a strong association with Trisomy 18 and other chromosomal abnormalities. ${ }^{71}$

Blazer et al prospectively assessed 46 consecutive pregnancies in which they identified the side of the present umbilical artery in fetuses with a single umbilical artery. ${ }^{72}$ The majority of cases were identified by transvaginal sonography between 14 and 16 weeks' gestation. A rightsided umbilical artery was detected in 25 fetuses (54.3\%), and a left-sided umbilical artery in 21 cases (45.7\%). Six fetuses (13\%) had associated anomalies, five of which were in the urinary system. No correlation was found between the type or severity of the malformations and the side of the missing (or present) umbilical artery. We concur with these authors that the exact location of a single umbilical artery can be reliably determined by ultrasonography from the beginning of the second trimester of pregnancy. The selection process of the missing (or present) vessel is likely random, even though the right single artery is seen slightly more frequently. ${ }^{72}$
Friebe-Hoffmann et al performed an analysis of 1169 women with singleton pregnancies diagnosed with SUA. ${ }^{73}$ Overall, 989 fetuses $(84.6 \%)$ had an isolated single umbilical artery, while 180 fetuses (15.4\%) had additional structural and/or chromosomal abnormalities. Fetuses with SUA exhibited lower birth weights (2825 grams versus 3220 grams $)(\mathrm{P}<0.001)$, increased rates of preterm delivery before 34 weeks' gestation $13.7 \%$ versus $3.8 \%$ (P $<0.001$ ), and sonographically estimated fetal weights to be lower than the 5 th centile $(21.6 \%$ versus $9.3 \%)(\mathrm{P}<$ $0.001) .{ }^{73}$ In $5.1 \%$ (60) infants, chromosomal or structural anomalies were detected following birth. Another recently published study (of $786(0.3 \%)$ of 233,123 deliveries) also found an isolated single umbilical artery, an independent predictor of adverse perinatal outcomes. ${ }^{74}$ Adverse outcomes associated with an isolated single umbilical artery included: placental abruption $(\mathrm{OR}=3.4)$, umbilical cord true knot of the umbilical cord $(\mathrm{OR}=3.5)$, umbilical cord prolapse $(\mathrm{OR}=2.8)$, and induction of labor and Cesarean delivery ( $\mathrm{OR}=1.5$ and $\mathrm{OR}=1.9$, respectively, compared to the control group and perinatal mortality rates were higher both antenally (IUFD OR=8.1) and postnatally (PPD $\mathrm{OR}=6.1)^{74}$

In fetuses with a single umbilical artery, the entire blood flow to the placenta is delivered through only one umbilical artery, which results in a compensatory increase in the single arterial diameter. Sepulveda at al measured umbilical vein and umbilical artery diameters in 55 fetuses with a single umbilical artery and in 55 with a normal three-vessel cord matched for gestational age. ${ }^{75}$ In all but one fetus with a single umbilical artery, the diameter of the umbilical artery was greater than $50 \%$ of that of the umbilical vein, resulting in an umbilical vein-to-umbilical artery ratio of $\leq 2$. In contrast, none of the fetuses with a three-vessel cord had a ratio of $\leq 2$. Increasing the diameter of the umbilical artery without modification of the diameter of the vein was therefore noted as a characteristic prenatal ultrasonographic feature of a single umbilical artery, rendering this interesting (and logical) observation, a useful technique for the detection of this vascular anomaly in utero. ${ }^{75}$

As mentioned earlier, the presence of two umbilical arteries may be seen as an "inherent protection system" of the fetus in the event of compression of the umbilical cord preceding delivery. In the event of compression of the umbilical artery, the Hyrtl anastomosis between the two umbilical arteries enables potential unimpaired continuation of placental perfusion despite the compression, or 
even complete cessation of flow in one of the umbilical arteries. This potential cord compression safety mechanism is notably absent in the presence of a single umbilical artery. Following documentation of a fetus with a single umbilical artery, further complicated by the presence of a double nuchal cord, during electronic fetal monitoring, we noted a prolonged fetal bradycardia necessitating immediate Cesarean delivery of an uncompromised neonate. ${ }^{64}$ We hypothesized that the umbilical cord compression with the double nuchal cord might have been considerably compromised by the absence of a second "protective" umbilical artery. ${ }^{64}$ Furthermore, we similarly observed other occurrences of double nuchal cord in association with a single umbilical artery in which prolonged fetal bradycardias in the third-trimester necessitated immediate Cesarean delivery of non-compromised neonates on at least on two other separate occasions. Although the potential impact of a single umbilical artery and possible associated diminished capability of the fetus to tolerate compression of the nuchal cord(s) has not been reported by others, we recommend increased fetal testing (prolonged fetal heart rate monitoring) when documenting the co-existence of these two otherwise unassociated events [nuchal cord(s) in the presence of a known single umbilical artery] occur simultaneously, and are more likely to necessitate delivery upon notation of fetal heart rate changes.

\section{Supernumerary Umbilical Veins}

Supernumerary umbilical veins represent a rare structural anomaly of the umbilical cord often (yet not always) associated with additional fetal anomalies. Painter and Russell described the notation of a four-vessel umbilical cord (containing two umbilical arteries and two umbilical veins) in an autopsy of a macerated stillborn infant. ${ }^{76}$ This finding (which was noted throughout the entire length of the umbilical cord) was thought to have resulted from the rare persistence of the right umbilical vein, which, as described previously, usually regresses. Additional structural anomalies included ectopia cordis, a symmetrical bifid liver, bilateral cleft lip and palate with absent soft palate and uvula. A similar report of a newborn with a four-vessel umbilical cord (containing two umbilical arteries and two umbilical veins) was similarly attributed to a persistent right umbilical vein associated with fetal hydrops and hypertrophic cardiomyopathy. ${ }^{77}$ The infant succumbed at 4 hours of age due to circulatory and respiratory insufficiency. Puvabanditsin et al reported a fetus with a four-vessel umbilical cord (throughout the entire length of the cord) also attributed to a rare persistence of the caudal portion of the right umbilical vein, with numerous associated structural anomalies including: agenesis of the cerebellar vermis, dextrocardia, situs ambiguous, atrioventricular canal, hypoplastic left ventricle and aortic arch, bilateral superior vena cava, interrupted inferior vena cava, and malrotation of the intestines. ${ }^{78}$ The infant survived after multiple corrective surgeries.

Interestingly, an unusual case in which a prenatal ultrasound at 28 weeks' gestation demonstrated a singleton growth-restricted fetus and oligohydramnios with a single umbilical artery containing a supernumerary (persistent right) umbilical vein, was reported in $2013 .^{79}$ Stillbirth occurred at 30 weeks' gestation. Pathology assessment of the umbilical cord confirmed the sonographic findings. ${ }^{79}$ Although no external gross fetal structural anomalies were noted, the parents declined an autopsy.

In contrast, a supernumerary umbilical vein is not always associated with dire prognosis, as cases with prenatal sonographic depiction of this condition have been reported without adverse neonatal outcomes. ${ }^{80,81}$

\section{Supernumerary Umbilical Arteries}

Other than being in association with conjoined twins (see following), cases of $>2$ umbilical arteries are extremely rare. Du et al reported a rare occurrence of stillbirth at 33 weeks' gestation with subsequent notation (and histopathology confirmation) of three umbilical arteries and one vein throughout the entire length of the umbilical cord. ${ }^{82}$ Although no external gross fetal structural anomalies were noted, the parents declined autopsy. The etiology of this unusual event is unclear, yet may reflect abnormal fusion of the paired dorsal aortas during early embryogenesis or alternatively, during embryogenesis, when the primitive umbilical arteries connect with the descending aorta. $^{82}$

\section{Supernumerary Umbilical Vessels Associated with Conjoined Twins}

A multi-vessel umbilical cord is considered a prenatal sonographic indicator of possible conjoined twinning. ${ }^{83}$ Numerous variations in supernumerary umbilical vessels (including combinations of two to four arteries and one to four veins) have been reported in association with conjoined twins. $^{83}$ 
Hecht et al described four such cases. ${ }^{84}$ In the first case, each umbilical cord contained three vessels (two arteries and one vein) and accounted for six umbilical vessels in the merged part of the umbilical cord. In the second case, the merged umbilical cord contained four vessels (two single arteries and two veins). In the third and fourth cases, the merged umbilical cord contained only three vessels (two arteries, one vein). These authors concluded that the above observations likely reflect that the development of the umbilical vessels occurs during late embryogenesis (8-12 days after fertilization) before the twinning process of conjoined twins begins (day 13). Thus, the development of the umbilical cord vessels should not be affected by the twinning process, and that the type of conjoined twins and the extent of sharing of fetal organs may influence the number of umbilical cord vessels. These authors concluded that it appears that the fewer vessels within the umbilical cord of conjoined twins, the more complex the fetal fusion. ${ }^{84}$

A recent prenatal sonographic diagnosis of thoracoomphalopagus conjoined twins in our unit at 23 weeks' gestation depicted an umbilical cord with a single umbilical vein and four umbilical arteries throughout the length of the entire umbilical cord (Figure 3).

Thomas et al described prenatal sonographic diagnosis of appropriate for gestational age, monochorionic diamniotic twins with an unusual single umbilical cord containing two veins and four arteries, which subsequently divided into two separate umbilical cords, each with three vessels, two umbilical arteries and one umbilical vein. ${ }^{85}$

\section{Forked Umbilical Cords in Twins}

Fraser et al reported liveborn monoamniotic twins with a forked umbilical cord. Pathology examination confirmed a marginally inserted two-vessel umbilical cord bifurcating at an $8 \mathrm{~cm}$ distance from the placenta into two separate three-vessel umbilical cords supplying each twin. ${ }^{86}$ Prenatal sonographic diagnosis of cases of forked umbilical cord of monochorionic monoamniotic, monochorionic diamniotic and conjoined twins has been reported. ${ }^{85,87-90}$

\section{Coiling of the Umbilical Cord}

Umbilical cord coiling, present from the mid-first trimester, represents another teleological protective mechanism protecting the umbilical cord from lateral shearing and potential compression forces.
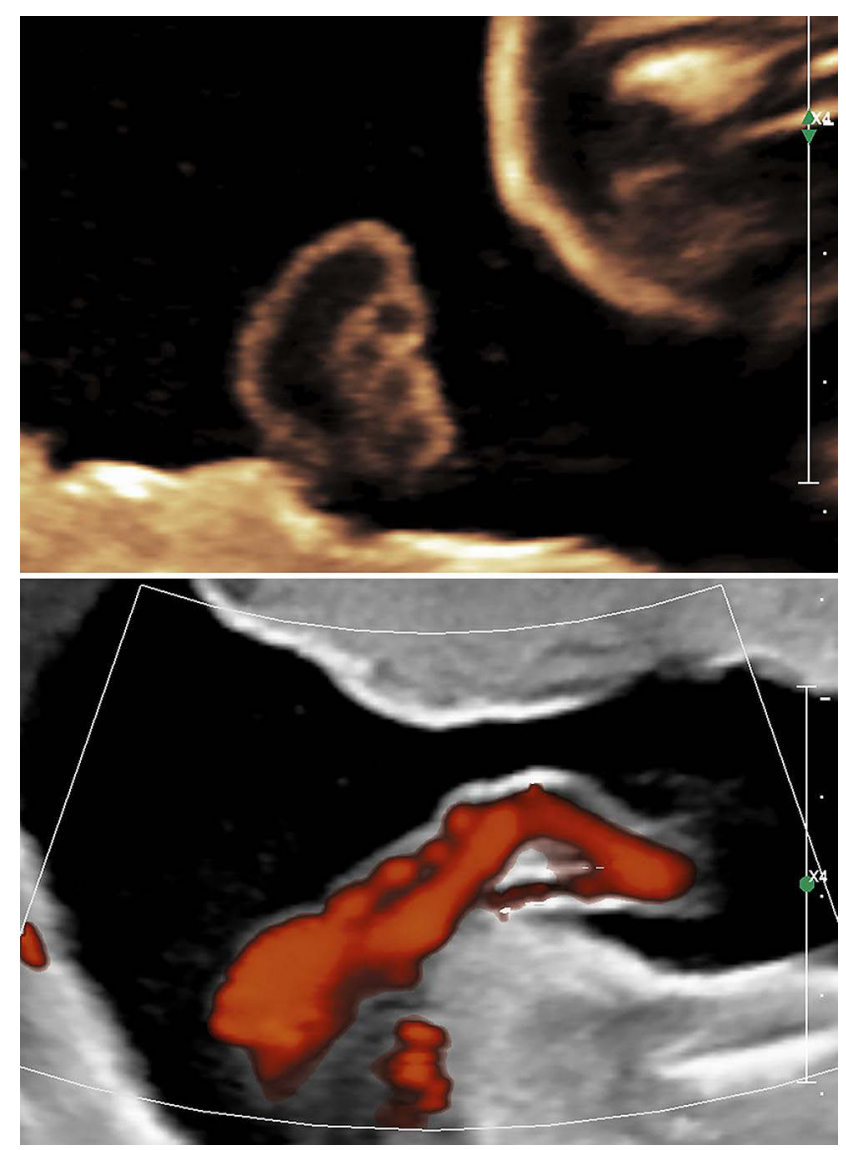

Figure 3 Umbilical cord of thoraco-omphalopagus twins at 23 weeks' gestation. Upper panel: Axial image of the umbilical cord of thoraco-omphalopagus twins at 23 weeks' gestation. Note the single umbilical vein and four (4) umbilical arteries (vessels are depicted en face). Lower panel: Doppler energy imaging of thoracoomphalopagus twins at 23 weeks' gestation. This image depicts a sagittal view of the umbilical vein, and adjacent four umbilical arteries. As in upper panel, note the single umbilical vein and four (4) umbilical arteries.

\section{Decreased Coiling}

Strong et al (recognizing the absence of these protective mechanisms of the umbilical cord with decreased coiling) noted clinical findings suggesting that fetuses with noncoiled umbilical blood vessels are at increased risk for perinatal morbidity and mortality. ${ }^{91}$ To quantitate umbilical vascular coiling, Strong and associates described the coiling index by dividing the total number of complete umbilical vascular coils by the umbilical cord length in centimeters. $^{91}$ The mean umbilical coiling index $=0.21 \pm$ 0.07 (SD) coils per centimeter. ${ }^{91}$ An increased risk of adverse perinatal outcomes is associated with decreased umbilical cord coiling. Among fetuses with umbilical coiling index values $\leq 10$ th centile, these authors noted a significantly greater incidence of karyotype abnormalities $(\mathrm{P}=0.04)$, meconium-staining $(\mathrm{P}=0.03)$, and operative 
delivery of fetal distress $(\mathrm{P}=0.03)$. There was a significantly greater incidence of moderate or severe variable fetal heart rate decelerations for fetuses with umbilical coiling index value $\leq 10$ th centile $(0.1 \mathrm{coils} / \mathrm{cm})$ or $\geq 90$ th centile $(0.3 \mathrm{coils} / \mathrm{cm}) .{ }^{91}$ These investigators later reported that among 200 consecutive live-born infants, the mean umbilical coiling index among those with nuchal cords $(0.18 \pm 0.09$ coils $/ \mathrm{cm})$ was significantly lower than among the group without nuchal entanglement $(0.21 \pm$ 0.07 coils $/ \mathrm{cm}), \mathrm{P}=0.01 .{ }^{92}$ Among fetuses with umbilical coiling indices $\leq 0.0$ coils $/ \mathrm{cm}, 42 \%$ had nuchal cords, while in contrast only $4.8 \%$ of infants with umbilical cords indices $\geq 0.3$ coils $/ \mathrm{cm}$ had nuchal cords $(\mathrm{P}=0.007)$. These authors thus reported an association between the density of umbilical vascular coiling and nuchal entanglement. ${ }^{92}$

Rana et al in 1995 assessed 635 placentas and umbilical cords from deliveries $>24$ weeks' gestation and noted that patients with hypocoiled cords $(<10$ th centile) exhibited higher rates of fetal heart rate (FHR) abnormalities and interventional delivery than among patients with normocoiled umbilical cords $[28.6 \%$ versus $15.9 \%(\mathrm{P}=0.01)$ and $19 \%$ versus $7.1 \%(\mathrm{P}=0.002)$, respectively]. ${ }^{93}$

\section{Increased Coiling of the Umbilical Cord}

Hypercoiling of the umbilical cord has been associated with an increased risk of adverse perinatal outcome. ${ }^{94}$ Ernst et al in 2013 defining hypercoiled umbilical cords ( $>3$ coils/ $10 \mathrm{~cm}$ ) assessed 318 placentas/umbilical cord with hypercoiled umbilical cords and assigned major umbilical gross coiling patterns (undulating, rope, segmented and linked, each with progressively deeper indentations in cord diameter). ${ }^{94}$ The rope pattern was the most common $(52 \%)$, followed by the undulating (26\%), segmented $(19 \%)$ and linked (3\%) patterns. Segmented and linked gross coiling patterns significantly correlated with histologic evidence of chronic fetal vascular obstruction and stillbirth, compared with the rope and undulating patterns. Cords with right twists significantly correlated with histologic evidence of chronic fetal vascular obstruction and stillbirth compared with cords with left twists. Interestingly, in this study, the number of cord coils per $10 \mathrm{~cm}$ did not correlate with any of the outcome variables. ${ }^{94}$

In the previously mentioned study by Rana et al, patients with hypercoiled umbilical cords ( $>90$ th centile) compared with those with normocoiled umbilical cords exhibited higher rates of premature delivery $[33.3 \%$ versus $12 \%(\mathrm{P}<0.0001)$ and increased incidence of cocaine use $12.7 \%$ versus $3.3 \%(\mathrm{P}=0.0006)$, respectively]. ${ }^{93}$
Machin et al reported frequencies and clinical correlations of abnormally coiled cords among 1329 cases referred for placental pathology assessment. ${ }^{95}$ Of cases assessed, $21 \%$ were "overcoiled" and $13 \%$ "undercoiled". Correlations noted in association with "overcoiled" cords were; stillbirth (37\%), fetal intolerance to labor $(14 \%)$, fetal growth restriction (10\%), and chorioamnionitis (10\%). For "undercoiled" cords, the frequencies of these outcomes were, $29 \%, 21 \%, 15 \%$ and $29 \%$, respectively. Abnormal coiling was associated with thrombosis of chorionic plate vessels, umbilical venous thrombosis, and cord stenosis. ${ }^{95}$

Interestingly, emerging data from twin gestations do not support a genetic basis for the umbilical cord coiling index. ${ }^{65,96}$ In addition, the previously mentioned study by Cromi et al confirmed that among all twin pairs, a discordant umbilical coiling pattern was observed between donor and recipient twins. These authors' prevalence of uncoiled and hypocoiled umbilical cords was higher among donor twins, while hypercoiling and atypical coiling occurred more frequently among recipient twins. ${ }^{65}$

\section{Discordant Umbilical Arteries}

Dolkart et al, in 1996, first described discordance in size between the umbilical arteries in six patients. ${ }^{97}$ Crosssectional and longitudinal views from multiple locations of the three vessel umbilical cords documented size discrepancies in a total of 23 serial assessments. Doppler evaluations of the dissimilar arteries demonstrated discordant flow velocity waveforms. The mean difference between the small and large artery systolic diastolic ratios (S/D) was significant $(\mathrm{P}<0.0001)$. Interestingly, two of the six patients had adverse perinatal outcomes. Pathology assessment of the artery discordance was confirmed by both gross and microscopic evaluation of the umbilical cords following delivery. ${ }^{97}$

Petrikovski and Schneider in 1996 reported regarding "hypoplastic umbilical artery" (defined as a three-vessel umbilical cord with an artery-artery diameter discordance of $>50 \%$ ), identifying 12 such cases over six years. ${ }^{98}$ Associated abnormalities included: trisomy $18 \quad(\mathrm{n}=1)$, polyhydramnios $(n=1)$, congenital heart disease $(n=1)$, fetal growth restriction $(n=2)$. Maternal diabetes was present in four cases. Thus, these authors noted that the presence of a hypoplastic umbilical artery is associated with increased perinatal morbidity and congenital abnormalities, with a high incidence of diabetes, and concluded that the prenatal finding of a hypoplastic umbilical artery 
should be followed with echocardiography and increased fetal surveillance. ${ }^{98}$

In contrast, Raio et al, in 1998, reported discordance between umbilical arteries in 14 of 1012 patients. ${ }^{99}$ Umbilical artery diameters and areas differed significantly between discordant arteries [diameter $2.9(1-4.3)$ versus 4.5 (3.8-6.5) mm $\mathrm{P}<0.001$; area $6.6(0.78-15.5)$ versus 16.25 (11.33-33.16)]. Significant discordance between umbilical artery diameters was confirmed after delivery. Abnormal insertion of the umbilical cord or a placental anomaly was noted in 6 of the 14 cases with umbilical artery discordance. Perinatal death occurred only in a trisomic infant born at 24 weeks' gestation. These authors concluded that newborns with discordant umbilical arteries are generally uncompromised, yet placental anomalies are common among this group of patients. ${ }^{99}$

Later, Predanic and Perni in 2006 concurred, noting that umbilical artery diameter discordance of $29.5 \%$ (the 95th centile) was not associated with increased adverse perinatal outcome. ${ }^{100}$

Thus, the significance of umbilical arteries discordant in diameter remains undetermined.

\section{Structural Abnormalities of the Umbilical Cord}

\section{Furcate Insertion of the Umbilical Cord}

In this rare condition, as the name suggests, the umbilical vessels branch and separate from the umbilical cord substance prior to insertion in the placenta (Figures 4 and 5). ${ }^{1}$ Thus, the umbilical vessels distal to the branching are left unprotected by Wharton's jelly and are covered only by amnion epithelium and as such, remain prone to thrombosis and injury. ${ }^{1}$ Fatal fetal hemorrhage has been associated with this condition following rupture of the umbilical vein at the site of insertion of the umbilical cord. ${ }^{101}$ Prenatal sonographic diagnosis of furcate insertion of the umbilical cord has been reported infrequently. ${ }^{102-104}$ Given the fixed anatomical location of this rare, potentially lethal condition, the application of color Doppler imaging and the recommendation by governing bodies that the placental insertion of the umbilical cord should be documented when possible, this condition may be reported more frequently.

\section{Velamentous Insertion}

Velamentous insertion occurs when umbilical vessels unsupported by either umbilical cord or placental tissue

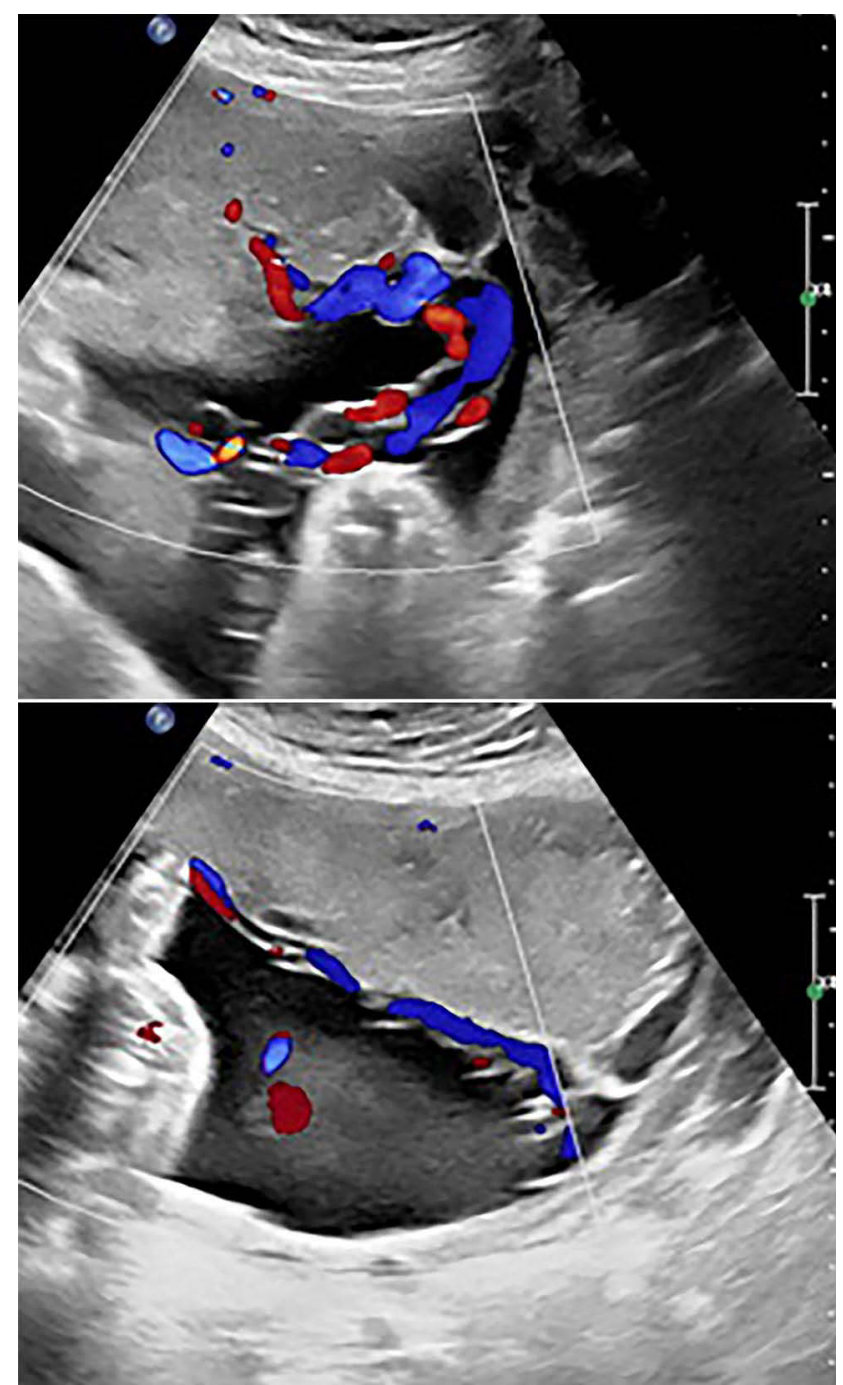

Figure 4 Monochorionic diamniotic twin gestation with reverse twin arterial perfusion (TRAP) sequence at 32 and I/7 weeks' gestation. Upper panel: Note furcate, marginal insertion of umbilical cord of the pump (normal twin). Lower panel: The umbilical cord of the pump twin feeds directly to the umbilical cord of the acardiac twin's placenta. The short and hypocoiled umbilical cord of the acardiac twin (image) contains two vessels and does not communicate with the placenta.

traverse the fetal membranes between the amnion and chorion prior to insertion in the placenta and are noted in approximately $1 \%$ of singleton term deliveries. ${ }^{1,105,106}$ This condition is associated with multiple gestations and a single umbilical artery. ${ }^{1}$ Complications of velamentous insertion of the umbilical cord include compression during labor - resulting in non-reassuring fetal status potential rupture of membranous vessels (usually the umbilical vein), arterial or venous thrombi, or the presence of vasa previa. ${ }^{1}$ In a retrospective cohort study of 482,812 pregnancies, $0.48 \%$ were complicated by velamentous cord insertion. ${ }^{105}$ Pregnancies complicated by velamentous cord insertion were associated with an increased risk of 


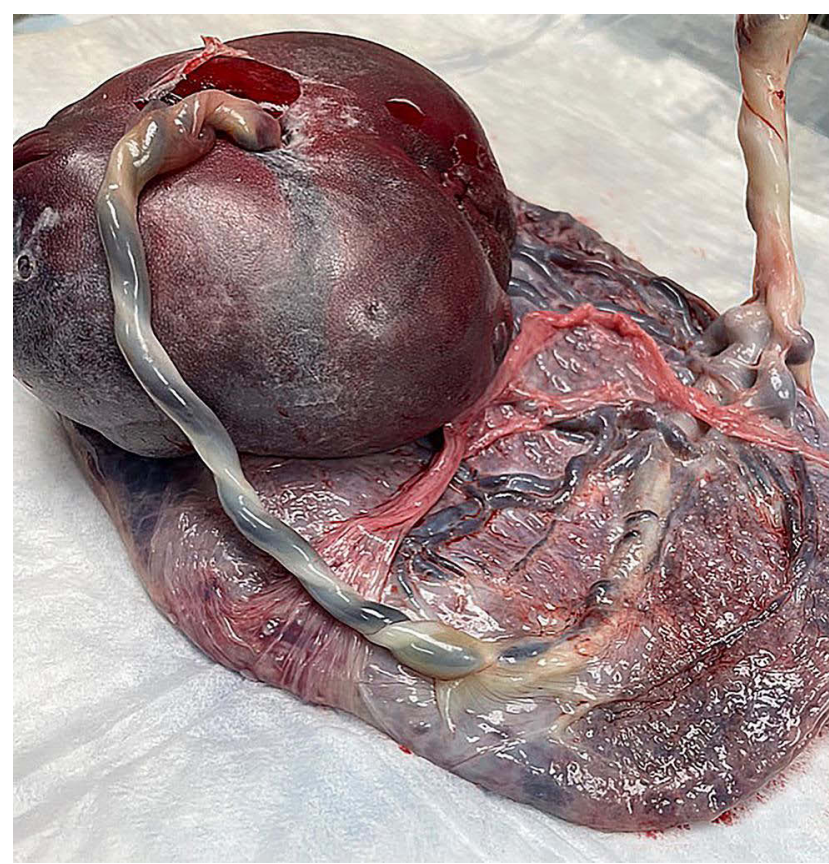

Figure 5 Post delivery image of the placenta and respective umbilical cords of a monochorionic diamniotic twin gestation with reverse twin arterial perfusion (TRAP) sequence delivered spontaneously at 38 weeks' gestation. Note marginal furcate insertion of the umbilical cord (Figure 4A) of the pump (normal twin) on the right. The umbilical cord of the pump twin feeds directly to the umbilical cord of the acardiac twin's placenta. The umbilical cord of the acardiac twin contains two vessels and does not communicate with the placenta (Figure 4B).

stillbirth $(2.6 \%$ vs $0.28 \%, \mathrm{p}=0.001)$, small for gestational age $(16.93 \%$ vs $10.17 \%)$, preterm delivery $<37$ weeks $(12.5 \%$ vs $9.1 \%, p=0.001)$, manual removal of the placenta $(14.47 \%$ vs $0.76 \%, \mathrm{p}=0.01)$, and postpartum hemorrhage $(6.66 \%$ vs $2.88 \%, \mathrm{p}=0.001)$. The adjusted odds for stillbirth after adjusting for confounders was more than nine times higher among pregnancies complicated by the presence of velamentous cord insertion (aOR 9.56; 95\% CI 6.76-13.5) vs those without velamentous cord insertion. ${ }^{105}$ Similar confirmation that isolated velamentous cord insertion is associated with adverse perinatal outcomes in singleton (and twin) gestations was reported in 2018 in a case-control study by Sinkin et al. ${ }^{107}$

Heinonen et al reported increased associations with preterm labor $(\mathrm{OR}=2.12)$, low 1 and 5 minute Apgar scores $(\mathrm{OR}=1.76$, and 2.47, respectively), small-forgestational age $(\mathrm{OR}=1.54)$ and abnormal intrapartum fetal heart rates $(\mathrm{OR}=1.59) .{ }^{108}$

Buchanan-Hughes et al in a systematic review reported an incidence between $0.4 \%$ and $11 \%$ in singleton pregnancies with an increased incidence among twin pregnancies $r$ (1.6-40\%). ${ }^{109}$ The incidence of velamentous insertion was increased among in-vitro fertilization (IVF) pregnancies and nulliparous women, and was found to be associated with adverse perinatal outcomes including preterm delivery, emergency Cesarean delivery in singleton pregnancies, and perinatal mortality among twins. ${ }^{109}$

Prenatal sonographic diagnosis of velamentous insertion of the umbilical cord has been reported as early as the first-trimester. ${ }^{10,111}$ Following utilization of color Doppler imaging, the sensitivity and specificity of prenatal sonographic diagnosis of this condition have improved considerably and range between $69 \%$ and $100 \%$ and between $95 \%$ and $100 \%$, respectively. ${ }^{112-115}$

\section{Velamentous Insertion in Twins}

The incidence of velamentous insertion is increased among twin gestations. ${ }^{106,107,116}$ Associated adverse perinatal outcomes of velamentous cord insertion among twins are reportedly higher than those associated with singleton gestations. ${ }^{107}$ Fries et al in 1993 studied 38 cases of monochorionic-diamniotic twins were identified, 11 of which manifested as twin-twin transfusion syndrome. ${ }^{117}$ The prevalence of velamentous cord insertion in the transfusion syndrome group was $63.6 \%$, compared with $18.5 \%$ in those without $(\mathrm{P}<0.01)$. Twin-twin transfusion syndrome pregnancies with velamentous insertions were delivered at significantly earlier gestational ages; had fewer surviving infants and were more likely to have been treated prenatally than transfusion syndrome pregnancies without velamentous insertion, although these latter two findings were not significantly different. These authors concluded that velamentous cord insertions are more common in twin-twin transfusion syndrome pregnancies and may contribute to the development of clear discordance in fluid volumes, following that the membranously inserted cord can be easily compressed, reducing blood flow to one twin. Reduction amniocentesis may reduce this compressive force on the cord insertion, thus explaining the success of this mode of intervention. ${ }^{117}$

Lee et al recently studied pathologically confirmed velamentous cord insertions and perinatal outcomes of 941 sets of twins with prenatal sonographic diagnosis, according to chorionicity. ${ }^{116}$ The prevalence of velamentous insertion in dichorionic twins and monochorionic twins was $5.8 \%$ and $7.8 \%$, respectively $(\mathrm{P}=0.251)$. The prevalence of vasa previa and placenta accreta sequence was higher among patients with versus those without velamentous insertion ( $P=0.008$ and 0.022 , respectively). Among monochorionic diamniotic twin gestations with 
velamentous cord insertion, birth weight, 1 and 5 minute Apgar scores were lower than dichorionic twins with velamentous insertion $(\mathrm{P}=0.01,0.002$ and 0.000$)$. There was no significant association between velamentous insertion and selective fetal growth restriction $(\mathrm{P}=0.486)$, twintwin transfusion syndrome $(\mathrm{P}=0.4)$, and birth weight discordance $(>20 \%$ and $>25 \%)(\mathrm{p}=0.378$ and 0.168 , respectively) in monochorionic diamniotic twins. ${ }^{17}$ Although these authors did not note a difference in the incidence of velamentous insertion based upon chorionicity, other authors have reported a higher incidence of velamentous insertion among monochorionic versus dichorionic twins. ${ }^{118}$

Of note, the presence of velamentous insertion of the umbilical cord among monochorionic twin gestations in a study by Castro-Costa et al of 630 monochorionic twin gestations was not associated with the development of twin-twin transfusion syndrome but was associated nevertheless with an increase in adverse perinatal outcome. ${ }^{118}$ The presence of velamentous insertion in one twin was significantly associated with small for gestational age (SGA) status (OR: 1.45, 95\% CI 1.13-1.87), and severe birth weight discordance (OR 3.09, 95\% CI 1.93-4.96). In addition, a significant interaction between twin-twin transfusion and velamentous insertion was noted when considering stillbirth and gestational age at birth. The prevalence of stillbirth in monochorionic pregnancies without twintwin transfusion increased from $4.6 \%$ to $14.1 \%$ in the presence of velamentous insertion $(P=0.027)$. In the twin-twin transfusion group, the prevalence of stillbirth was comparable in the absence or presence of velamentous insertion. Similarly, gestational age at birth was significantly lower in the presence of velamentous insertion only in the non-twin-twin transfusion group. Thus, these authors concluded that velamentous insertion is not associated with the development of twin-twin transfusion syndrome but increases the risk of adverse outcomes. ${ }^{118}$ Both velamentous insertion and twin-twin transfusion (independent of each other) increase the prevalence of stillbirth and lower gestational age at birth in a similar fashion, demonstrating that velamentous cord insertion is an important indicator of adverse perinatal outcome among monochorionic twins. ${ }^{118}$ In a similar study, Yonetani et al assessed 357 monochorionic diamniotic twin gestations, noting that velamentous insertion was present in both twins in $2.5 \%$ of cases and in at least one twin in $22.1 \%$ of cases. ${ }^{119}$ These authors concurred with a previous study by Costa-Castro that velamentous insertion in monochorionic twin pregnancies is not a risk factor for twin-twin transfusion syndrome, yet differed in that they noted an association between velamentous insertion and the risk of severe perinatal morbidities. ${ }^{119}$ The observation that velamentous cord insertion and unequal placental territory are not critical factors for the development of twin-twin transfusion syndrome was supported by a study of 76 monochorionic placentas with TTTS and 63 monochorionic placentas by Lopeiore et al. ${ }^{120}$ Couck et al studied 518 monochorionic pregnancies and concluded that velamentous cord insertion in one or both twins will increase the risk of adverse outcome and twin-twin transfusion syndrome. ${ }^{121}$

Khalafat et al studied 497 twin gestations, 351 (70.6\%) of which were dichorionic and 146 (29.4\%) were monochorionic and confirmed that monochorionic twins with velamentous insertion are at increased risk of birth weight discordance and selective fetal growth restriction. ${ }^{122}$

In a meta-analysis and systematic review of twenty studies regarding this topic, Lin et al note data that suggest an association between velamentous insertion and birth weight discordance and selective fetal growth restriction. ${ }^{123}$ Notwithstanding, they noted that the association between velamentous cord insertion and twin-twin transfusion may be overestimated, and that further research is required. ${ }^{123}$ Thus, the contribution, if any, of velamentous insertion in the development of twin-twin transfusion and overall adverse perinatal outcome in these patients is not without controversy and remains undetermined. Sherer et al also reported an association between velamentous umbilical cord insertion and growth discordance among twins. ${ }^{124}$

Finally, Gulersen et al noted an interesting case of prenatal sonographic diagnosis of velamentous insertion of the cord in the intervening membrane between twins. ${ }^{125}$

\section{Succenturiate Placenta}

Prenatal sonographic diagnosis of succenturiate (and bilobate) placenta, both similarly potential predisposing factors for vasa previa, have been reported. ${ }^{126-130}$ Sonographic findings of these similar entities are rather straightforward and consist of the notation of placental tissue without continuity (occupying areas at a distance from each other) yet connected by fetal vasculature.

\section{Vasa Previa}

Vasa previa is a rarely reported condition in which fetal blood vessels, unsupported by either the umbilical cord or placental tissue, traverse the fetal membranes within the 
lower segment of the uterus caudal to the presenting part. Undetected vasa previa carries a high fetal mortality rate (ranging between $33 \%$ and $100 \%$ ) due to potential catastrophic fetal hemorrhage following rupture of fetal membranes. ${ }^{131-133}$ Vasa previa has been reported to occur at an incidence of between $0.07 \%$ and $0.08 \%$ of deliveries, ${ }^{134-136}$ or alternatively at $0.46-1$ per 1000 deliveries $^{137-140}$ or $1: 2500$ deliveries, ${ }^{141}$ or 2.1 per 10,000 deliveries, ${ }^{142}$ or considerably higher at approximately 1:260 IVF pregnancies, ${ }^{134}$ This condition lends itself with relative ease to prenatal transvaginal sonographic diagnosis. Interestingly, approximately $85 \%$ of cases of vasa previa have one or more identifiable risk factors, including multiple gestations, in-vitro fertilization, bilobed, multilobed, succenturiate-lobed, low-lying placentas, and velamentous insertion of the umbilical cord. $^{132,134,143}$ Approximately $11 \%$ of cases are without existing risk factors. ${ }^{144}$

In a multicenter study of 155 pregnancies complicated by the presence of vasa previa, Oyelese et al reported an overall perinatal mortality of $36 \%(55 / 155) .{ }^{133}$ In $39 \%$ $(61 / 155)$ of cases, vasa previa was diagnosed prenatally; $97 \%$ of neonates with prenatal sonographic diagnosis survived (59/61) compared with 44\% (41/94) in cases without prenatal diagnosis $(\mathrm{P}<0.001)$. Median 1 and 5 minute Apgar scores in cases with prenatal diagnosis were 8 and 9, versus 1 and 4, respectively, among survivors without prenatal diagnosis $(\mathrm{P}<0.001)$. More than half $(24 / 41)$ of survivors born to mothers without prenatal diagnosis required blood transfusion versus 2/59 of those diagnosed prenatally $(\mathrm{P}<0.001)$. The only predictors of neonatal survival were prenatal diagnosis $(\mathrm{P}<$ $0.001)$ and gestational age at delivery $(\mathrm{P}=0.01) .{ }^{133}$ These authors concluded that favorable outcomes with this condition depend upon prenatal diagnosis and indicated Cesarean delivery at 35 weeks' gestation (or earlier should rupture of membranes, labor, or significant hemorrhage occur). ${ }^{133}$

Ruiter et al performed a systematic review of the accuracy of ultrasound in the prenatal diagnosis of vasa previa with papers scored on methodological quality by using the Quality Assessment of Diagnostic Accuracy Studies Tool (QUADAS-2), extracting sensitivity and specificity data. ${ }^{138}$ The QUADA-2 tool reflected poor methodology in six of the eight studies, and prenatal detection rates ranged between 53\% (10/19) and 100\% (total of 442,633 patients) including 138 vasa previa cases. In the two prospective studies $(n=33,795$ patients including 11 cases of vasa previa), midtrimester transvaginal ultrasound color Doppler imaging detected all cases (sensitivity, $100 \%$, specificity ranging between $99.0 \%$ and $99.8 \%) .{ }^{138}$ Catanzarite and Kulkarni reported similarly high specificities regarding prenatal diagnosis of vasa previa of $91 \%$ and $94.3 \%$, respectively. ${ }^{145,146}$

It should be noted that patients with mid-trimester sonographic diagnosis of vasa previa, may subsequently undergo spontaneous resolution of this condition with advancing gestational age. ${ }^{147}$ In a retrospective cohort study of 100 patients with prenatal diagnosis of vasa previa (defined as the presence of a fetal vessel within $2 \mathrm{~cm}$ of the internal os) at a mean gestational age of $22.8 \pm 4.9$ weeks' gestation, 39 patients (39\%; 95\% CI 30-49\%) were noted to have a resolution at a mean gestational age of $28.6 \pm 4.7$ weeks. ${ }^{147}$ Factors associated with vasa previa resolution included an earlier gestational age at diagnosis (aOR 6.1; 95\% CI 1.92-19.4), vasa previa, which did not cover the internal os (aOR 8.29, 95\% CI 2.79-24.62), and vasa previa was not the result of resolution of placenta previa (aOR 2.85, 95\% CI 1.01-8.03). These authors advocate that patients with vasa previa should be observed serially to assess for possible subsequent vasa previa resolution, following that many will resolve in the third trimester. $^{147}$

Following that correct prenatal sonographic diagnosis of vasa previa is essential in achieving favorable neonatal results, Ranzini and Oyelese detail practical points and useful tips in the sonographic screening evaluation of patients for vasa previa. ${ }^{140}$

Of note, the International Society of Ultrasound in Obstetrics and Gynecology (ISUOG), the American Institute of Ultrasound in Medicine (AIUM) and the Royal College of Obstetricians and Gynecologists (RCOG) do not currently recommend screening for vasa previa, ${ }^{140}$ yet such has been noted to be effective in some reports. $^{135,148,149}$ Current ACOG/SMFM guidelines recommend Cesarean delivery in prematurity at approximately 35 weeks' gestation following sonographic diagnosis of this potentially life-threatening condition. ${ }^{149,150}$

Correct prenatal diagnosis of vasa previa is critical to prevent intrapartum stillbirth as a result of fetal exsanguination. Despite the absence of sufficient evidence to support the universal mid-gestation ultrasound screening, recent data indicate the need for standardized prenatal targeted screening protocols for patients at increased risk of vasa previa. ${ }^{138,140,143}$ Ranzini and Oyelese recently 
stressed the three steps necessary for screening for vasa previa. $^{140}$

1. Detailed assessment of the umbilical cord insertion site.

2. Verify the absence of a bi-lobe or succenturiate lobe of the placenta.

3. Detailed assessment of the lower uterine segment in all patients with spontaneous resolution of lowlying or placenta previa, later in the pregnancy.

In our unit, emphasis is placed upon the identification of the velamentous insertion and the presence of succenturiate lobes of the placenta, both predisposing factors for vasa previa. Furthermore, close attention is given to color Doppler imaging in the proximity of the internal OS of the cervix during uniform mid-trimester screening for cervical length as recommended by ACOG.

Zhang et al, in retrospectively assessed data from prospective screening for vasa previa among 26,830 singleton pregnancies, which included $21(0.08 \%)$ with vasa previa, advocate a two-stage method of screening for vasa previa. ${ }^{135}$ During the 11-13-week ultrasound assessment, umbilical cord insertion was identified as central in 93.4\% of cases, marginal in $6.3 \%$ of cases, and velamentous in $0.3 \%$ of cases. In 16 of the 21 patients with vasa previa $(76.2 \%)$ cord insertion at the first-trimester scan was classified as velamentous at the inferior part of the placenta, in two cases $(9.5 \%)$ as marginal and in three cases (14.3\%) central. ${ }^{135}$

Interestingly, Sinkey and Odibo found that within baseline cost calculations, transvaginal sonographic screening for vasa previa was the most cost-effective when performed in patients with IVF pregnancies. ${ }^{151}$ Melcer et al assessed medical records of early multiple pregnancies that resulted in singleton fetuses diagnosed with vasa previa. ${ }^{152}$ A statistically significant difference in the prevalence of vasa previa among pregnancies that started as multiple gestations but continued later as singletons compared to multiple pregnancies $(8.8 \%$ vs $0.2 \%$, respectively, $\mathrm{P}<0.0001$ ) was noted. The OR for vasa previa in pregnancies that began as multiple gestations but resulted in singleton pregnancies was 41.1 (95\% CI 12.77-131.94), suggesting that it might be worthwhile to consider all twins at the beginning of pregnancy to be at increased risk of vasa previa, irrespective of the actual number of live fetuses during later stages of gestation. ${ }^{152}$
Magnetic resonance imaging prenatal diagnosis of vasa previa in association with a bilobed placenta has been reported. ${ }^{153}$ Similarly, three-dimensional and pulsed sonography have been utilized in the prenatal sonographic diagnosis of vasa previa. ${ }^{154}$

In a review study, Jauniaux et al confirmed that the incidence of twin gestations diagnosed with vasa previa in cohort and case-control studies was $11 \%$ and concluded that there is sufficient evidence to warrant guidelines for targeted screening. ${ }^{155}$

An association of vasa previa with IVF pregnancies was also reported by Oyelese et al and Isotton et al. ${ }^{156,157}$

\section{Marginal Insertion of the Umbilical Cord}

Of note, it appears that attention should also be directed at sonographic depiction of marginal umbilical cord insertion (Figures 4 and 5) in that this condition has been associated with an increase in both adverse maternal and perinatal outcomes. ${ }^{106,158}$ In case-controlled study in 2019 Nkwabonh et al noted a prevalence of $7.2 \%$ associated with preeclampsia $(\mathrm{aOR}=2.94,95 \%$ CI $1.14-7.59)$, placental abruption $(\mathrm{OR}=33.68,95 \%$ CI 9.8-115.76), nuchal cords (aOR 3.07, 95\% CI 1.69-5.59), low birth weight (aOR 3.15, 95\% CI 2.46-9.045) and NICU admission (OR $4.72,95 \%$ CI $2.46-9.04) .{ }^{158}$

\section{Umbilical Cord (Funic) Presentation}

Umbilical cord (funic) presentation is defined as such when the presenting part of the fetus consists of the umbilical cord with intact fetal membranes (in contrast to umbilical cord prolapse with rupture of the membranes) lends itself to sonographic diagnosis and was first reported by Christopher and later Vintzileos et al in 1983. ${ }^{159,160}$ Funic presentation has been associated with marginal cord insertion in a low-lying placenta. ${ }^{161}$ Clearly, intrapartum prenatal sonographic diagnosis of this condition, or alternatively close to (and not remote from) delivery, may allow Cesarean delivery prior to labor, thus bypassing the feared potential life-threatening surgical emergency of prolapse of the umbilical cord. It should, however, be recognized that cord presentation remote from delivery does not predict this condition in labor. Ezra et al in 2003 conducted two separate studies regarding this matter. ${ }^{162}$ In the first study: 16,551 delivery records were analyzed, noting that 42 patients had clinical cord prolapse at delivery. Prenatal ultrasound assessments were available in $16 / 42$ patients. Only two of the sixteen (12.5\%) had previous documentation of cord presentation. In 
the second study: cord presentation was documented in 13 of 8122 consecutive ultrasound assessments $(0.16 \%)$. Six of the patients underwent only one scan. Three of these 13 patients $(23 \%)$ required cesarean delivery due to malpresentation, and cord presentation. The remaining seven patients underwent repeat ultrasound assessment, which confirmed persistent umbilical cord presentation in three (23\%). All these three patients were delivered by indicated Cesarean (one for umbilical cord prolapse). The other four patients spontaneously converted to vertex presentations, with spontaneous resolution of the cord presentation at delivery. Thus, these authors recommend that the current practice upon diagnosis of funic presentation in the thirdtrimester requires repeat prenatal and intrapartum sonographic assessments to determine the presence or absence of this condition, and accordingly, mode of delivery. ${ }^{162}$ Color Doppler imaging has clearly aided prenatal sonographic depiction of this condition. ${ }^{163}$

Interestingly, Jo et al reported an unusual case in which a large amniocele (measuring $15 \times 15 \mathrm{~cm}$ ), containing loops of umbilical cord, was sonographically depicted herniating through a spontaneous uterine rupture (in an unscarred uterus) at 23 weeks' gestation. ${ }^{164}$ At laparotomy, hemoperitoneum $(1000 \mathrm{~mL})$ with uterine rupture was confirmed, with the entire gestational sac containing the fetus protruding through the uterine wall. The infant, weighing 700 grams, succumbed. ${ }^{164}$

\section{Functional Disorders of the Umbilical Cord}

\section{Umbilical Vessel Thrombosis}

Prenatal sonographic diagnoses of umbilical artery and umbilical venous thrombosis, respectively, have been reported. Predisposing factors include: excessive umbilical cord length, hyper-coiling of the umbilical cord, and deficient Wharton's jelly. ${ }^{165}$

\section{Umbilical Artery Thrombosis}

Umbilical artery thrombosis is an uncommon prenatal event, associated with placental hypoperfusion and increased rates of perinatal morbidity including fetal organ damage (infarcts), fetal growth restriction, and stillbirth. ${ }^{166-170}$ Pathogenesis of this condition is unclear, yet predisposing factors appear to include; long cord, peripheral cord insertion, short cord with twists, and funisitis. ${ }^{168}$ Interestingly, Donepudi et al recently reported an umbilical artery aneurysm (with favorable neonatal outcome) following multiple intrauterine transfusions (for management of $\mathrm{Rh}$ alloimmunization). ${ }^{70}$ In a clinicopathological report of findings in 11 cases (occurring between 33 and 40 weeks' gestation Sato and Benirschke reported $3 / 11$ cases (38\%) with severe fetal growth restriction, and stillbirth in two cases (25\%)). All 11 cases were noted to exhibit partial necrosis of the vascular wall. ${ }^{168}$ Shilling et al in 2014 reported 7 cases occurring over a 13-year period at a tertiary referral center with more than 10,000 deliveries annually. ${ }^{167}$ Two of the seven cases were stillborn, and 3 of the additional cases were small for dates. ${ }^{167}$ Although many cases are only detected at autopsy and placental and umbilical cord assessment following stillbirth, prenatal sonographic reports of this rare condition have been reported. ${ }^{165,166,170,171}$ Prenatal sonographic depiction of a single umbilical artery (following earlier depiction of two umbilical arteries) should alert to the possibility of this condition, even in the absence of direct vision of the aneurysm. ${ }^{171}$

\section{Umbilical Venous Thrombosis}

Umbilical vein thrombosis is a rare condition, which entails dilatation of the umbilical vein-varix. ${ }^{172}$ This condition is associated with very high perinatal mortality, although favorable outcomes have been reported. ${ }^{172-175}$ Considered predisposing factors include: compression, torsion, stricture, or hematoma of the umbilical cord. ${ }^{173}$ In contrast to umbilical artery thrombosis, the danger inherent to umbilical vein thrombosis lies with the single nature of the vein in contrast to the presence of a potential compensatory umbilical artery (other than in cases of a single umbilical artery). Other considerable differences between umbilical vein versus umbilical artery thrombosis lay in the unique function of the single umbilical vein in delivery of oxygenated blood to the fetus and potential release of emboli from the thrombus downstream towards the fetus, rather than towards the placenta with its inherent redundancy, as in the case of umbilical artery thrombosis. ${ }^{172}$

Prenatal sonographic diagnosis of thrombosis of the umbilical vein has been reported (Figures 6 and 7) and entails focal dilatation of the umbilical vein (in contrast to varix, which will be discussed later), with an echogenic core (representing the thrombus) and at times, associated turbulent flow within the focally dilated umbilical vein segment, which contains the thrombus, which clearly is not completely occlusive. ${ }^{172-177}$ Intra-amniotic umbilical vein varix is characterized by a high frequency of thrombosis in the 

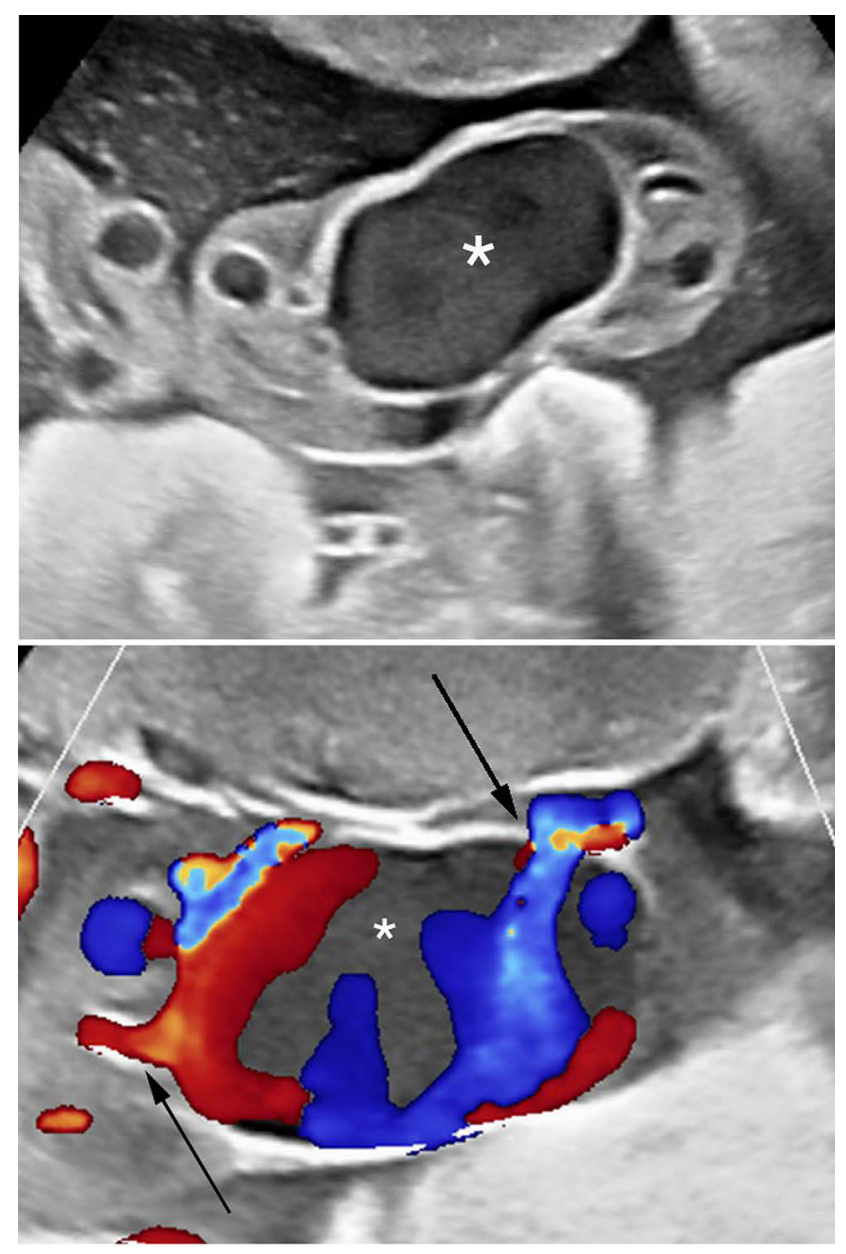

Figure 6 Upper panel: Real-time sonography depicting echogenic mass $(*)$ within the umbilical vein, considered consistent with umbilical vein thrombosis. Lower panel: Color Doppler sonography depicting echogenic mass within the umbilical vein, considered consistent with umbilical vein thrombosis. Black arrows point to the narrow venous inflow and outflow areas, respectively.

Notes: Reproduced from: Sherer DM, Dalloul M, Guerra R, Bahamon C, Abulafia O. Prenatal sonographic depiction of large intra-amniotic vein thrombosis. J Ultrasound Med. 2018;37(II):2733-2734. ${ }^{172} @ 2018$ by the American Institute of Ultrasound in Medicine. Published by John Wiley and Sons.

dilated umbilical vein. Clinical management remains unclear and is likely to depend upon gestational age at diagnosis. ${ }^{172}$ Although incidental findings at delivery suggest that not all cases are associated with adverse outcomes, it is clear that interval fetal testing may not suffice as stillbirth has occurred immediately or in relative proximity to reassuring fetal testing. ${ }^{76,175}$ Thus, it appears that following this diagnosis at relatively advanced gestational ages - delivery should be considered. ${ }^{172}$ Of note, thrombosis occluding a varix umbilical vein causing stillbirth, and a separate report of partial occlusion of an umbilical vein varix leading to emergency Cesarean delivery, has been reported (and will be detailed following). ${ }^{178,179}$
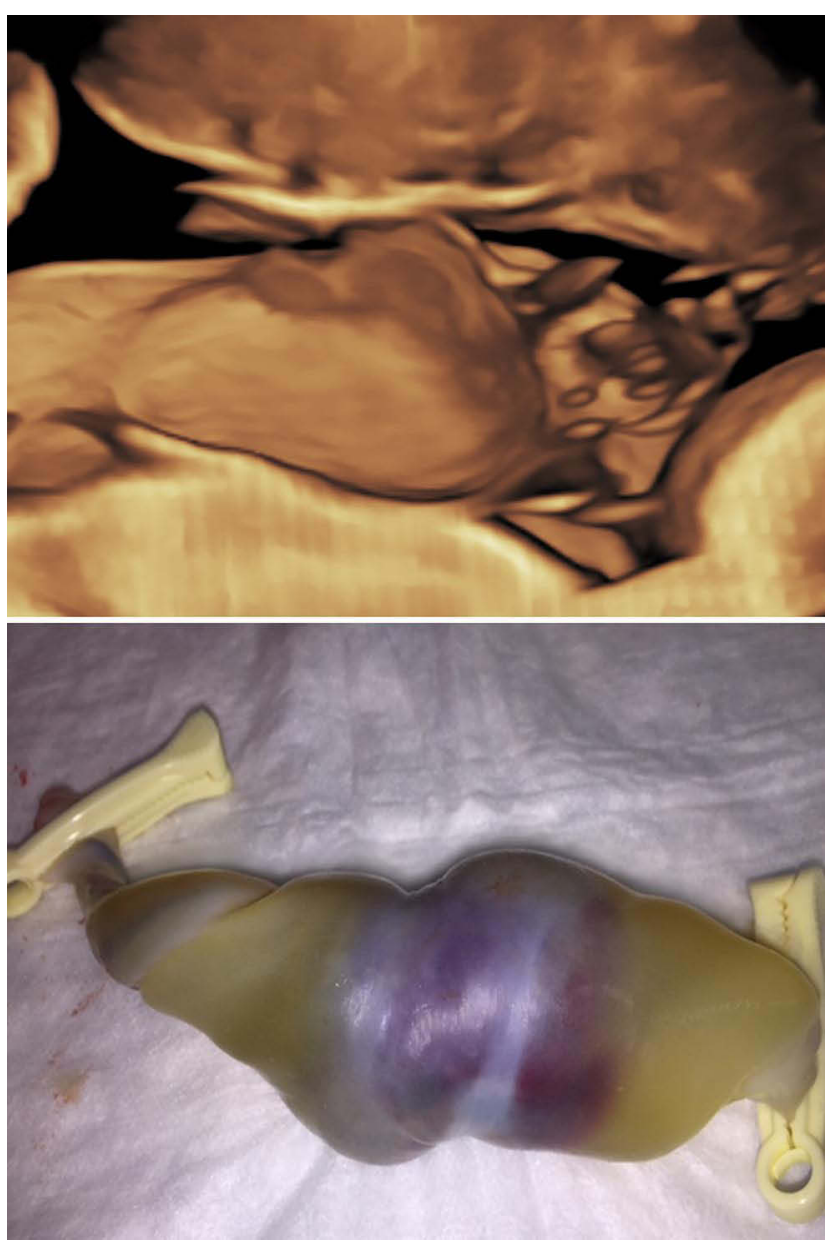

Figure 7 Upper panel: Three-dimensional sonography of the umbilical vein thrombosis. Lower panel: Umbilical vein thrombosis immediately following emergency Cesarean for prolonged fetal bradycardia at 37 weeks' gestation.

Notes: Reproduced from: Sherer DM, Dalloul M, Guerra R, Bahamon C, Abulafia O. Prenatal sonographic depiction of large intra-amniotic vein thrombosis. J Ultrasound Med. 2018;37(II):2733-2734. ${ }^{172}$ (C) 2018 by the American Institute of Ultrasound in Medicine. Published by John Wiley and Sons.

\section{Varix}

The umbilical vein varix indicates dilatation of the umbilical vein. The etiology of this condition is unclear, yet may this represent a weakness of the venous wall. ${ }^{176}$ This condition occurs more commonly in the intra-abdominal portion of the umbilical vein (between the abdominal wall and fetal liver), termed a fetal intra-abdominal umbilical vein varix (FIUVV). Umbilical varix is defined when the caliber is greater than $9 \mathrm{~mm}$ or with a ratio of $>50 \%$ between the dilated and a more distal normal intraabdominal portion of the vein (Figure 8). ${ }^{180-182}$

The incidence of this condition is relatively rare, occurring between 0.4 and 1.1/1000 deliveries and is associated with additional fetal anomalies in one-third of cases, ${ }^{183-185}$ 

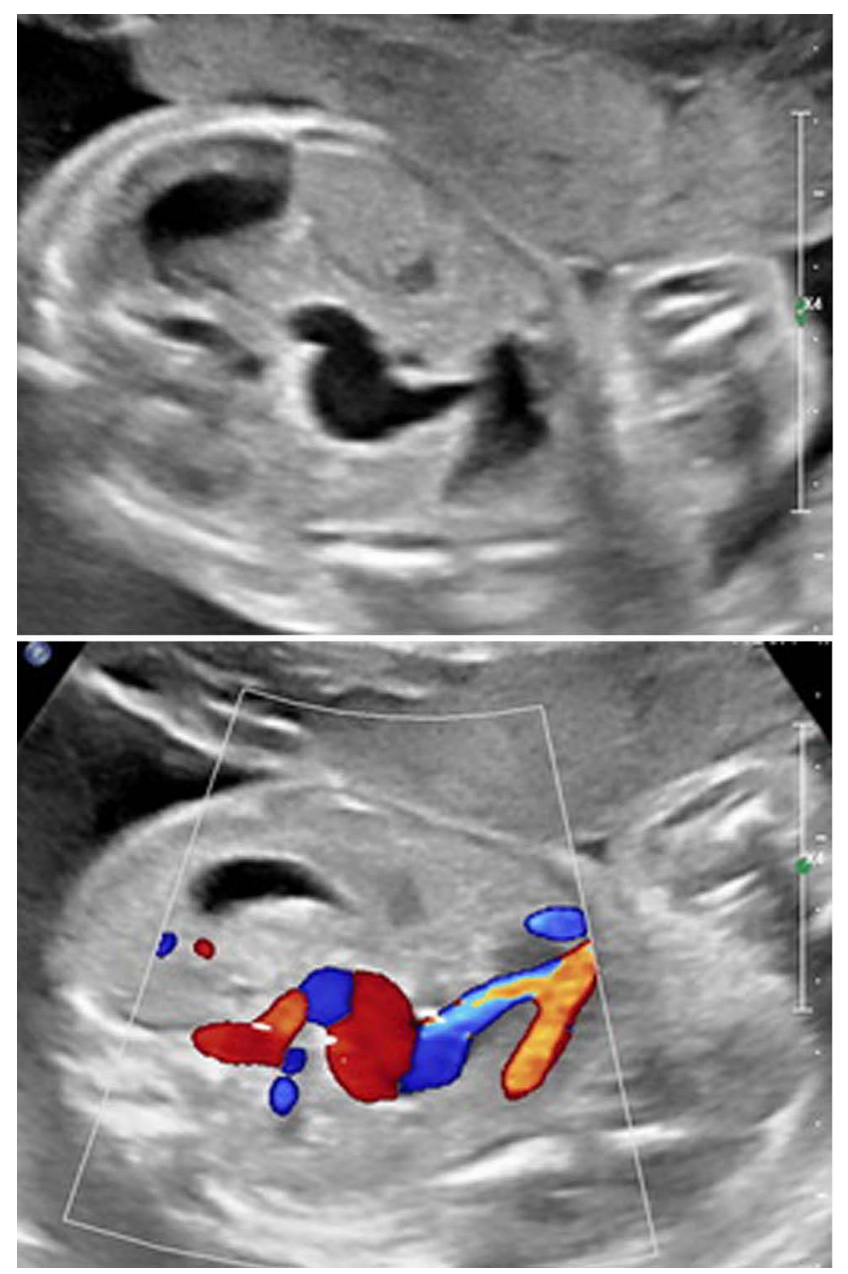

Figure 8 Fetal intra-abdominal varix at 24 and 5/7 weeks' gestation. Upper panel: Real-time ultrasound depicting the intra-abdominal aneurysmal dilatation of the umbilical vein. Lower panel: Color Doppler imaging confirming the venous vascular nature of this lesion.

fetal hydrops, stillbirth, ${ }^{186}$ fetal schistocytic hemolytic anemia, thrombocytopenia, ${ }^{187,188}$ and thrombosis. ${ }^{178}$ In general, in the absence of additional anomalies, the prognosis is usually favorable. ${ }^{184}$ An intra-abdominal UVV may be depicted as a cyst-like structure in the upper fetal abdomen containing venous flow upon color Doppler imaging (Figure 8).

A high rate of Cesarean deliveries was noted with this condition. ${ }^{176,189}$ Prenatal diagnosis is uncommon, ${ }^{176}$ and although thrombus formation is common within a varix, prenatal diagnosis of a thrombus within an umbilical vein varix is uncommon. ${ }^{172,176}$

Prenatal diagnosis of isolated fetal umbilical vein - varix has been reported. In a report of 14 such cases, WeissmanBrenner et al noted a median gestational age of 27.5 weeks' gestation at diagnosis (range: $22-34) .{ }^{189}$ The average diameter of the varix was $10.6 \mathrm{~mm}$ (range: $8-15$ ), and maximal diameter at follow-up was $12.8 \mathrm{~mm}$ (range: $10-18 \mathrm{~mm}$ ). Median gestational age at delivery was 36.1 weeks (range 34-40) average birth weight was 2834 grams (range 17253715 grams). Five patients (35.7\%) underwent emergency Cesarean delivery. Interestingly, among fetuses exhibiting turbulent flow in the varix, the authors noted a tendency towards larger maximal varix diameters, earlier gestational age at delivery, and lower birth weights. No stillbirths or neonatal deaths were reported. With this experience, these authors suggested that fetuses with umbilical vein varix be followed every week following diagnosis to 28 weeks' gestation and twice-weekly thereafter, with consideration for indicated delivery at 36-37 weeks' gestation or with any evidence of fetal compromise (Figure 8). ${ }^{189}$ The importance of the recommendation for close surveillance following diagnosis was demonstrated in a recently published case of delivery of patient at 32 weeks' gestation of a fetus with a varix (diagnosed at 23 weeks) due to a rapid increase in the peak systolic velocity (PSV) of the umbilical vein from $100 \mathrm{~cm} / \mathrm{s}$ to $150 \mathrm{~cm} / \mathrm{s} .{ }^{178}$ At emergency Cesarean birth, thrombosis of the umbilical cord was confirmed. The infant did well. Induction of labor has been recommended at 36-37 weeks' gestation. ${ }^{189}$ The differential diagnosis of a varix of the umbilical vein includes umbilical cord cyst/s. Babay et al initially considered the diagnosis of an umbilical cord cyst at prenatal sonography at 30 weeks' gestation, and only after unidirectional movement of echogenic particles was noted, was a large varix of the umbilical vein diagnosed, and later confirmed as such at histopathology. ${ }^{190}$

\section{Umbilical Vessel Aneurysm}

As elsewhere, umbilical vessel aneurysms are a complication of congenital thinning of the vessel wall. ${ }^{1}$

\section{Umbilical Vein Aneurysm}

Umbilical vein aneurysm has been associated with stillbirth. ${ }^{191}$ This condition is considered to result from a congenital weakness or thinning of the vessel wall. Prenatal sonographic diagnosis of this rare condition has been reported at 34 weeks' gestation. Subsequent pathology assessment confirmed the diagnosis. ${ }^{192}$ Prenatal sonographic diagnosis of umbilical vein aneurysm was reported with a live born infant delivered at term by Cesarean. ${ }^{193,194}$ In the case reported by Shipp et al, increasing size over time with the development of an intramural thrombus prompted premature delivery at 33 weeks' gestation. ${ }^{194}$ 


\section{Umbilical Artery Aneurysm}

Umbilical artery aneurysm represents an unusual and often fatal condition, which has been associated with Trisomy $18,{ }^{195,196}$ single umbilical artery, ${ }^{197}$ cardiac abnormalities, fetal growth-restriction, and stillbirth. ${ }^{198-201}$ Prenatal sonographic diagnosis of this rare condition has been reported infrequently and appears relatively straightforward (when visible), consisting of a focal enlargement/ dilatation of the umbilical cord. Color Doppler imaging will confirm the pulsatile arterial nature of blood flow. Echogenic structures within the aneurysm are likely to represent mural thrombus. ${ }^{197,201-204}$ Prenatal diagnosis as early as $22-23$ weeks' gestation has been reported by a number of authors, possibly reflecting mid-trimester formation of the umbilical artery aneurysm. ${ }^{198,200,205}$ Interestingly, according to Hill et al in the majority of cases, which described the precise anatomical location of the umbilical artery aneurysm (7/9), these were located at the placental insertion site. ${ }^{202}$ This area may be particularly prone to the development of umbilical artery aneurysm, following that this area typically is devoid of the protective Wharton's jelly. ${ }^{195,202}$ Clearly, following diagnosis, karyotype analysis (NIPT or amniocentesis), detailed sonographic assessment for additional anomalies, close fetal surveillance for interval growth, fetal wellbeing, and possible early delivery should be considered. In addition, given that the majority of umbilical artery aneurysms occur in association with a single umbilical artery ( $8 / 20$ according to Hill et al), and the wellestablished compensatory enlargement of a single umbilical artery, increased alertness for development of umbilical artery aneurysms in the event of a single umbilical artery, appear warranted. ${ }^{202}$ Care to avoid unwarranted trauma (even at Cesarean delivery) is recommended in that intraoperative rupture of a large umbilical artery aneurysm at Cesarean at 28 weeks' gestation with subsequent neonatal anemia, disseminated intravascular coagulopathy and death, has been reported by Matsuki et al. ${ }^{205}$ It is important to state that thrombus within the umbilical artery aneurysm is not always associated with stillbirth, and that the latter may occur in the absence of arterial thrombus formation. ${ }^{202}$

\section{Stricture of the Umbilical Cord}

The terms of stricture, constriction, coarctation, or torsion of the umbilical cord are considered synonymous. These occurrences may be spontaneous. ${ }^{206-209}$ or iatrogenic, usually following amniocentesis. ${ }^{209-212}$ It has been considered that the underlying cause of umbilical cord stricture is a primary deficiency of Wharton's jelly, a concept, which indirectly reflects/infers the previously detailed importance of this inherent protective mechanism of the cord. ${ }^{1}$ Absence of Wharton's jelly, stenosis, or obliteration of umbilical vessels, usually close to the fetal insertion of the umbilical cord and intravascular thrombosis at the narrowed segment of the cord are often noted. ${ }^{1,208}$ The location close to the fetal insertion may reflect the gradually decreasing amount of Wharton's jelly near the abdomen. ${ }^{1}$ Strictures of the umbilical cord are often noted in association with stillbirth, although rare cases of survival following emergency delivery have been noted, usually following notation of decreased fetal movements. ${ }^{1,207}$

Torsion of the umbilical cord has been implicated in fetal death. ${ }^{213,214}$ Rare cases of prenatal sonographic depiction of torsion in the umbilical cord have been reported. $^{215,216}$

The acute presentation of this usually lethal complication and rarely reported prenatal sonographic diagnosis of this condition suggest that detailed attention to the sonographic appearance of the umbilical cord (and especially the presence of Wharton's jelly) at or close to the fetal abdominal wall insertion of the umbilical cord are merited in the third-trimester when possible. Given the reports of recurrence of such (usually rare) events in subsequent pregnancies, special consideration of detailed sonographic depiction of the content of Wharton's jelly this anatomical location in women with previous loss(es) attributed to this condition, should be considered. ${ }^{217}$

\section{Umbilical Cord Cysts}

The differential diagnosis of rarely noted cystic structures located within the umbilical cord (and its insertion) include: true cysts, pseudocysts, omphalomesenteric duct cysts, vascular conditions, abdominal wall defects, bladder exstrophy, and urachal anomalies. ${ }^{218}$

Umbilical cord cysts are a rare occurrence and, when isolated, are usually of no clinical significance. True cysts are lined with epithelium and may represent a remnant of the allantois or from the omphalomesenteric duct during cord formation and are typically located in proximity to the fetal insertion of the umbilical cord. ${ }^{219-221}$ Cysts may reach several centimeters in diameter and may be detected in the first trimester. ${ }^{22}$ Pseuodocysts represent embryological remnants or cystic degeneration of Wharton's jelly that surrounds the cord and have no epithelial lining. ${ }^{1}$ Approximately up to $20 \%$ of umbilical cord cysts may 
be associated with structural or chromosomal abnormalities, most commonly Trisomy $18 .^{220}$

A number of studies have addressed the notation of umbilical cord cysts noted during the first -trimester. Ross et at in 1997 assessed 859 women with singleton live fetuses between 7 and 13 weeks' gestation. ${ }^{222}$ Umbilical cord cysts were present in 29/859 (3.4\%) of cases. Fetal anomalies were noted in $7 / 27$ of cases with continuing pregnancies. Fetal anomalies were more likely if the cyst was located in proximity to the distal (placental or fetal) ends of the umbilical cord (RR 3.3; 95\% CI 1.3-8.5), or paraaxially (RR 3.8 ; 95\% CI 1.2-12.0) or if the cyst persisted above 12 weeks' gestation (RR 7.7; 95\% CI 3.218.6). ${ }^{22}$ Sepulveda et al in 1999 followed nine pregnancies with first-trimester umbilical cord cysts, noting normal outcomes in all nine cases, suggesting that the incidental firsttrimester notation of an umbilical cord cyst is not associated with an increase in adverse pregnancy outcomes. ${ }^{223}$ Ghezzi et al in 2003 performed a similar assessment of umbilical cord cysts between 11 and 14 weeks' gestation, noting the prevalence of umbilical cord cysts was $2.1 \%$ (24/1159). ${ }^{224}$ The cysts were single and multiple in 18 and six cases, respectively. The median (range) largest umbilical cyst diameter did not differ between multiple and single umbilical cord cysts $3.8 \mathrm{~mm}(2.1-18)$ versus $3.05 \mathrm{~mm}(2.0-7.8), \mathrm{P}=$ 0.386 . All patients with single umbilical cord cysts delivered infants without structural anomalies, while among patients with multiple cord cysts, four had miscarriages and one fetus was noted to have obstructive uropathy. These authors concluded that while single umbilical cord cysts are associated with good outcomes, multiple umbilical cord cysts are associated with an increased likelihood of miscarriage and aneuploidy. ${ }^{224}$ Gilboa et al, reporting umbilical cysts at nuchal translucency screening, noted an incidence of $0.7 \%(8 / 1080)$. In five cases, the finding was isolated and resolved spontaneously. ${ }^{225}$ In three cases, additional structural anomalies were noted, and in all three cases the umbilical cord cyst persisted. One of the fetuses was noted to have a hypoplastic left heart with normal karyotype, and another had multiple malformations in association with Trisomy 18 . Both of these cases underwent termination of pregnancy. The third fetus had an ectopic kidney and patent urachus, which underwent spontaneous closure at 23 weeks, with a continued uneventful pregnancy. ${ }^{225}$

In contrast, persistent umbilical cord cystic masses in the second and third trimesters of pregnancy are associated with lethal aneuploidy and/or congenital anomalies. ${ }^{226,227}$

\section{Hematoma}

Umbilical cord hematoma is a rare etiology of stillbirth occurring in approximately 1 in 5500 live births. $^{228}$ Notwithstanding, the perinatal loss associated with this condition is $>50 \%$. $^{229,230}$

The majority of hematomas of the umbilical cord are iatrogenic, resulting from inadvertent laceration of umbilical vessels during amniocentesis, or alternatively, during intentional penetration of the umbilical vein at cordocentesis/intravascular blood transfusion..$^{231-235}$ In these cases is not unusual to sonographically observe active hemorrhage from the puncture site, at times with a gradually increasing echogenic mass with the umbilical cord - representing the extended umbilical cord hematoma.

In contrast, rare cases of spontaneous umbilical cord hematoma have been reported. ${ }^{22,229,236-241}$ Prenatal sonographic findings are similar to those with the above-described umbilical cord hematoma, yet without the preceding invasive procedure. This rare condition has been associated with a short umbilical cord (considered a potential etiologic factor), and umbilical cord cysts. ${ }^{230}$ Prenatal sonographic diagnosis of spontaneous umbilical cord hematoma consists of notation of cystic umbilical cord masses. Sepulveda reported two such cases, which were later complicated by fetal death. $^{237}$ Brown and Nicolaides in 2000 reported a similar occurrence complicated by fetal death at 28 weeks' gestation. $^{242}$ Spontaneous hemorrhage from the umbilical cord has been attributed to umbilical cord ulceration [associated with congenital upper intestinal (either duodenal or jejunal) atresia]. ${ }^{243}$ The above notwithstanding a massive umbilical hematoma may occur without adverse sequelae. ${ }^{238}$

\section{Umbilical Cord Tumors}

Few true tumors of the umbilical cord exist. These include a variety of hemangiomas, angiomyxomas and rare teratomas.

\section{Angioma/Hemangioma}

Hemangiomas are benign mesenchymal neoplasms composed of blood vessels. Histopathology usually reveals the presence of neoplastic vascular channels around larger, dilated "feeder" vessels. ${ }^{244}$ Hemangioma of the umbilical cord is an uncommon condition, considered to originate from endothelial cells of the umbilical vessels (most commonly an umbilical artery, less commonly the umbilical vein or both) and is usually found within segments of the umbilical cord distant from the placental and fetal 
insertions. $^{245}$ Gross pathology assessment depicts a fusiform-shaped swelling of the umbilical cord engulfed by edema of adjacent Wharton's jelly. ${ }^{244}$ This condition carries a high morbidity and mortality rate of approximately $35 \%$, often related to coexisting factors including rupture with resulting hemorrhage, nonimmune hydrops, polyhydraminios, fetal disseminated intravascular coagulopathy (DIC), fetal growth restriction, additional hemangiomas, other fetal anomalies, and stillbirth. ${ }^{244-249}$ Stillbirth may result secondary to mechanical obstruction of umbilical vessels by the tumor as suggested by Kamitomo et al who noted stenosis of the umbilical vein and an umbilical artery in association with this lesion. ${ }^{245}$ Interestingly, a number of reports have noted the presence of amnionic inclusion cysts and pseudocysts in association with hemangiomas. ${ }^{244,250,251}$ Elevated maternal midtrimester maternal serum alpha-fetoprotein levels have been reported in association with umbilical cord hemangiomas. $^{245,252-254}$

Prenatal sonographic diagnosis has been reported infrequently. ${ }^{194,245,248,253-256}$ Location and sonographic appearance of a hemangioma in close proximity to the abdominal wall have led to prenatal and neonatal misdiagnosis of an omphalocele. ${ }^{253}$ Prenatal sonographic findings include notation of a hyperechoic lesion or a multicystic mass within the umbilical cord. ${ }^{245,246,248}$ Color Doppler imaging will confirm the vascular nature of the lesion with depiction of multiple branching arterial vessels with low resistance at Doppler assessment. ${ }^{248}$ Interestingly, prenatal sonographic detection of an umbilical cord hemangioma was recently reported as an early sign of diffuse neonatal hemangiomatosis (DNH) with the newborn later diagnosed with multiple hemangiomas in the liver, intestines, skin and brain. $^{257}$

Although hemangiomas may occur at any point throughout the entire length of the umbilical cord, the fetal and placental insertion sites (both fixed and often sonographically depicted) should be scanned in detail.

\section{Umbilical Cord Hemangioma in Association with Klippel-Trenaunay-Weber Syndrome}

Klippel-Trenaunay-Weber syndrome is a vascular malformation syndrome consisting of varying involvement of cutaneous capillaries, veins, and lymphatics with hypertrophy of soft tissue and bones of affected limbs. This complex, developmental disorder reflects asymmetric hemi-hypertrophy of extremities and trunk due to asymmetrical bony and soft tissue overgrowth, varicose veins and cutaneous hemangioma. Clinical diagnosis entails the presence of at least two of the three considered classic findings of: localized cutaneous capillary malformations, venous abnormalities, and limb hypertrophy. This syndrome has also been defined as capillary-lymphaticvenous malformation, reflecting the changes seen in these vessels. Interestingly, two reports of prenatal ultrasonographic diagnosis of umbilical cord hemangioma in association with Klippel-Trenaunay-Weber syndrome have been reported. ${ }^{258,259}$

Sahinoglu et al reported a spheric weakly echogenic mass within the umbilical cord, later confirmed at postpartum examination as an umbilical cord hemangioma. ${ }^{258}$ Recently, in 2020, Yu et al reported prenatal sonographic diagnosis of Klippel-Trenaunay-Weber syndrome (mainly manifesting hypertrophy of the left thigh) associated with an umbilical cord hemangioma. ${ }^{259}$ These cases infer that upon consideration of Klippel-Trenaunay-Weber syndrome, the umbilical cord should be scanned in detail in search of possible umbilical cord hemangiomas.

\section{Angiomyxoma}

Angiomyxomas represent a rare subset of hemangiomas, with increased perinatal morbidity and mortality, ${ }^{260}$ which may arise from one or more of the umbilical vessels, or remnants of embryonic vessels. ${ }^{261}$ Potential prenatal complications may include compression of the main umbilical cord vasculature resulting in fetal growth restriction and possible stillbirth. ${ }^{261}$ Interestingly, these tumors have been reported in association with increased mid-trimester maternal serum alpha-fetoprotein levels. ${ }^{261,262}$ Histopathology assessment reveals a proliferation of thin-walled vessels, which are embedded in the myxoid stroma. ${ }^{263}$ At times, positive staining of endothelial cells within the tumor for factor VIIIrelated antigen has been reported. ${ }^{263}$ Despite their relative rarity, prenatal sonographic diagnosis is possible and consists of notation of a complex mass within the umbilical cord, which may contain cystic components. ${ }^{261-267}$ The majority of these tumors contain nodules attached to the cord, which may appear sonographically as focal hyperechogenic areas. $^{261}$ Angiomyxomas may reach a considerably larger size. Prenatal sonographic diagnosis of an angiomyxoma involving the entire length of the umbilical cord was reported by Jauniaux et al. Following that, the length of this umbilical cord was considered considerably shortened at approximately $30 \mathrm{~cm}$, a 3620-gram infant was delivered by Cesarean at 37 weeks' gestation. ${ }^{261}$ At delivery, length of the umbilical cord was $26 \mathrm{~cm}$, and varied between 2 and $8 \mathrm{~cm}$ 
in diameter. ${ }^{261}$ Wilson et al describe an angiomyxoma of the umbilical cord requiring partial in utero decompression of a large cystic component of the tumor $(16 \times 12 \times 5 \mathrm{~cm})$, which enabled spontaneous vaginal birth of an uncompromised infant at 36 weeks' gestation. ${ }^{264}$ Angiomyxomas may rarely manifest as components of arteriovenous malformation (usually of one umbilical artery or capillaries within the Wharton's jelly). Indeed, Zhang et al in 2021 described prenatal findings of a large angiomyxoma of the umbilical cord complicated by the presence of a massive arteriovenous malformation associated with stillbirth at 27 and 1/7 weeks' gestation. $^{267}$

\section{Teratoma}

Congenital mature teratomas (composed of mature tissues originating from more than one germ cell layer) of the umbilical cord are exceptionally rare. ${ }^{1}$ Umbilical cord teratomas contain solid and cystic components and have been detected at prenatal sonography following depiction of a predominantly solid heterogeneous mass. Definitive diagnosis depends upon histopathology assessment following delivery. ${ }^{268}$ Histology of a mature teratoma of the umbilical cord may at times reveal tissue derived from all three germ layers and teratomas, including: central nervous system tissue, cartilage, skin, bone and gastrointestinal tract, have been reported. Benign, mature teratomas of the umbilical cord are often associated with congenital malformations of the fetus of (including: omphalocele, duodenal atresia, exomphalos, hydrocephalus, meningomyelocele, umbilical hernia, single umbilical artery, atrioventricular canal defect), and rarely, chromosomal abnormalities. ${ }^{268-270}$

\section{Umbilical Cord Arteriovenous Malformation}

Congenital umbilical arteriovenous malformations in which blood flows freely between an umbilical artery and vein (in the absence of capillary network) are rare, and most commonly represent a neonatal condition involving the umbilicus, which may be asymptomatic (and found at the time of assessment of an umbilical hernia, or abdominal murmur), or alternatively may present acutely due to hemorrhage or high-output cardiac failure. ${ }^{271-275}$

Prenatal diagnosis of an arteriovenous malformation is extremely rare. ${ }^{276-278}$ Reported prenatal sonographic findings may include the initial finding of a large vascular tumor of the umbilical cord depicted with color Doppler imaging, or following indirect findings of fetal cardiomegaly.
Interestingly, an umbilical arteriovenous (AV) fistula suspected following clear depiction of a jet flow originating in one of the umbilical arteries entering a dilated umbilical vein (in one of dichorionic diamniotic twins) at 24 weeks' gestation and associated with mild concurrent cardiomegaly and dilatation of the inferior vena cava, was following by spontaneous in-utero resolution of this vascular anomaly and favorable neonatal outcome after induction of labor and vaginal birth of appropriate for gestational infant at 36 weeks' gestation. $^{279}$ As mentioned previously, Zhang et al in 2021 described a fetus at 23 and 27 week's gestation with an umbilical cord angiomyxoma measuring $8.8 \times 6.5 \mathrm{~cm}$ located in proximity to the placental insertion of the umbilical cord. ${ }^{267}$ The mass was characterized by a central hyperechoic area surrounded by peripheral multicystic hypoechoic areas. HDlive flow depicted that the internal vessels of the mass were fed by the two umbilical arteries and drained into the umbilical vein, serving as massive arteriovenous shunts. Stillbirth occurred at 27 weeks' gestation. The presence of an angiomyxoma $(10.2 \times 6.5 \mathrm{~cm})$ was confirmed by pathology examination. The authors proposed that stillbirth may have been the result of volume overload resulting from the massive arteriovenous malformation or alternatively mechanical compression of umbilical vessels. ${ }^{267}$

\section{Current Recommendations for Sonography of Umbilical Cord Morphology}

The PRACTICE PARAMETER for the Performance of Standard Diagnostic Obstetrical Ultrasound of the American College of Radiology (ACR), American College of Obstetricians and Gynecologists (ACOG), Society of Maternal Fetal Medicine (SMFM), Society of Radiology of Ultrasound (SRU), ACR-ACOG-AIUMSMFM-SRU, regarding the umbilical cord published in 2018, simply states: "The umbilical cord should be imaged and the number of vessels in the cord documented. The placental cord insertion site should be documented when technically possible". ${ }^{280}$ In a similar fashion, the International Society of Ultrasound in Obstetrics and Gynecology (ISUOG) does not address the topic of umbilical cord morphology. ${ }^{281}$

In addition, the Society for Maternal Fetal Medicine (SMFM) in the detailed Consult Series \# 37 entitled "Diagnosis and management of vasa previa", further recommends: "Ultrasound evaluation of placental location and the relationship between the placenta and internal 
cervical os should be included at the second-trimester ultrasound scan, and the placental cord insertion site should be documented when technically possible" and that "Follow-up ultrasound should be performed at 32 weeks of gestation for women who were diagnosed with placenta previa or low-lying placenta at mid-trimester ultrasound examination. Since placenta previa is detected in the middle of the second trimester that later resolves and low-lying placenta even if it later resolves are associated with vasa previa and consequently high perinatal mortality rates, transvaginal ultrasonography with color and pulsed Doppler is recommended to rule out vasa previa". ${ }^{50}$

Specific MR imaging criteria for utilization of detailed depiction of umbilical cord entanglement (nuchal, true knots and complex entanglement) remain to be determined. ${ }^{282}$

Thus, these governing bodies support:

1. Assessment of the number of vessels within the umbilical cord.

2. Sonographic assessment of the fixed points of the umbilical cord (both fetal and placental insertions of the umbilical cord).

3. Assessment of possible vasa previa at midtrimester fetal anatomy assessment/transvaginal screening of cervical length.

These guidelines clearly avoid any attempt to obtain sonographic measurements of the umbilical cord, or Wharton's jelly or potential abnormal umbilical cord morphology. Also, not addressed by the governing bodies are the topics of cord entanglement (nuchal cords, true knots of the umbilical cord, or complex entanglement of the umbilical cord) discussed in detail elsewhere. ${ }^{12-14}$

Respectfully, we submit that the entire length of the umbilical cord available for sonographic assessment should be scanned in detail for potential umbilical cord morphology abnormalities discussed earlier in this article. In the foreseeable future, sonographic resolution will undoubtedly continue to improve, followed by increased diagnostic accuracy. Potential widespread application of Color Doppler, Power Doppler, 3D ultrasound in conjunction with other imaging diagnostic tools (CT and/or MR imaging with currently available 3D computer-assisted reconstruction techniques) will likely further advance prenatal assessment of morphology of the umbilical cord throughout its entire length and the increase in the frequency of notation of any the wide array of rare prenatal diagnoses of abnormal morphology of the umbilical cord detailed earlier. Threedimensional reconstruction of CT or MR is of special interest in that these imaging techniques may enable depiction of the length of umbilical cord located behind the fetal body, currently inaccessible to transabdominal sonography.

It appears we should be prepared for these promising imaging eventualities and maintain awareness of the widearray of (albeit rare) potential umbilical cord morphology abnormalities, and upon encountering such conditions seek further depiction utilizing additional imaging technologies other than standard sonography.

\section{Summary}

The umbilical cord, an often under-appreciated, yet vital human organ essential for the developing fetus with its inherent redundancy and resilience, regretfully does not lend itself with ease to detailed sonographic evaluation throughout its entire length. Future imaging capabilities, including computed tomography or magnetic resonance imaging with 3D computer-assisted reconstruction techniques, may enable detailed assessment of the entire umbilical cord length, currently not accessible to sonography due to fetal positioning and other limitations of sonography. Other than a single umbilical artery, anomalies of the umbilical cord are uncommon yet may be associated with potential fetal compromise. In addition to nuchal loop(s), true knot(s) of the umbilical cord and complex umbilical cord entanglement not covered in this Commentary yet detailed elsewhere, ${ }^{12-14}$ umbilical cord complications associated with potential fetal compromise/stillbirth, including: umbilical venous and arterial thrombosis, rare tumors (such as hemangioma, angiomyxoma and teratoma), vasa previa may be detected with prenatal sonography, with alert and attentive scanning, as these anomalies may be missed with relative ease. Given the critical function of the umbilical cord in fetal development until such imaging technologies become widely available, it is incumbent upon sonographers to utilize every opportunity (including during repeat sonographic assessments) to evaluate those portions of the umbilical cord availing themselves in real-time to insonation, and potentially utilize other above-mentioned imaging technologies if/when appropriate.

\section{Disclosure}

The authors report no conflicts of interest in this work. 


\section{References}

1. Benirschke K, Kaufman P. Anatomy and pathology of the umbilical cord and major fetal vessels. In: Benirschke K, Kaufman P, editors. Pathology of the Human Placenta. 3rd ed. New York, NY: Springer-Verlag; 1995:319-377.

2. Raio L, Ghezzi F, Di Naro E, Franchi M, Bruhwiler H. Prenatal assessment of the Hyrtl anastomosis and evaluation of its function: case report. Hum Reprod. 1999;14(7):1890-1893. doi:10.1093/humrep/14.7.1890

3. Raio L, Ghezzi F, Di Naro E, Balestrei D, Duria P, Scheinder H. In-utero characterization of the blood flow in Hyrtl anastomosis. Placenta. 2001;22(6):597-601. doi:10.1053/plac.2001.0685

4. Liu LC, Huang HB, Yu MH, Su HY. Analysis of intrauterine fetal demise - a hospital based study in Taiwan over a decade. Taiwan J Obstet Gynecol. 2013;52:546-550. doi:10.1016/j.tjog.2013.10.016

5. Lehtonen T, Marrkula T, Soidinsalo P, Otonkonski S, Laine J. Causes of stillbirth in Turku, Finland, 2001-2011. Pediatr Dev Pathol. 2017;20(1):5-15. doi:10.1177/1093526616686236

6. Hammad IA, Blue NR, Allhouse AA, et al.; the NICHD Stillbirth Collaborative Research Network Group. Umbilical cord abnormalities and stillbirth. Obstet Gynecol. 2020;135:644-652. doi:10.1097/AOG.0000000000003676

7. Parast MM, Crum CP, Boyd TK. Placental histologic criteria for umbilical blood flow restriction in unexplained stillbirth. Hum Pathol. 2008;39(6):948-953. doi:10.1016/j.humpath.2007.10.032

8. Ryan ED, Trivedi N, Bernirschke K, Lacoursiere DY, Parast MM. Placental histologic criteria for diagnosis of cord accident: sensitivity and specificity. Pediatr Dev Pathol. 2012;15(4):275-280. doi:10.2350/11-12-1127-OA.1

9. Singh V, Khanum S, Singh M. Umbilical cord lesions in early intrauterine fetal demise. Arch Pathol Lab Med. 2003;127(7):850-853. PMID 12823040. doi:10.5858/2003-127-850-UCLIEI

10. Sherer DM, Anyaegbunam A. Prenatal ultrasonographic assessment of the umbilical cord: a review Part I. Obstet Gynecol Surv. 1997;52:515-523. doi:10.1097/00006254-199708000-00023

11. Sherer DM, Anyaegbunam A. Prenatal ultrasonographic assessment of the umbilical cord: a review Part II. Obstet Gynecol Surv. 1997;52:506-514. doi:10.1097/00006254-199708000-00022

12. Sherer DM, Amoabeng O, Dryer A, Dalloul M. Current perspectives of prenatal sonographic diagnosis and clinical management challenges of true knot of the umbilical cord. Int $J$ Womens Health. 2020;12:221-233. doi:10.2147/IJWH.S192260

13. Sherer DM, Ward K, Bennett DM, Dalloul M. Current perspectives of prenatal sonographic diagnosis and clinical management challenges of nuchal cord(s). Int $J$ Womens Health. 2020;12:613-631. doi:10.2147/IJWH.S211124

14. Sherer DM, Roach C, Soyemi S, Dalloul M. Current perspectives of prenatal sonographic diagnosis and clinical management challenges of complex entanglement of the umbilical cord Int $J$ Womens Health. 2021;13:247-256. doi:10.2147/IJWH S285860

15. Rayburn WF, Beyen A, Brinkman DE. Umbilical cord length and intrapartum complications. Obstet Gynecol. 1981;57:450-453.

16. Ente G, Penzer PH. The umbilical cord: normal parameters. J R Soc Health. 1991;111(4):138-140. doi:10.1177/146642409111100406

17. Algreisi F, Brown R, Shrim A, Albasri SF, Shamarani H, AlZoubiadi A. Effect of long and short umbilical cord upon perinatal outcome. IJRCOG. 2016;5(12):4228-4231. doi:10.18 203/2320-1770.ijrcog/20164042

18. Berg TG, Rayburn WF. Umbilical cord length and acid-base balance at delivery. $J$ Reprod Med. 1995;40(1):9-12. PMID 7722985 .

19. Schmid A, Jacquemyn Y, Loor JD. Intrauterine growth restriction associated with excessively long umbilical cord. Clin Pract. 2013;3(2):e23. PMID 24765511. doi:10.4081/cp.2013.323
20. Zbeidy R, Souki FG. One long umbilical cord, four nuchal loops and a true knot. BMJ Case Rep. 2017;2017:bcr2017-223241. PMID 29222212.

21. Taweevisit M, Thorner PS. Massive fetal thrombotic vasculopathy associated with excessively long umbilical cord and fetal demise: case report and literature review. Pediatr Dev Pathol. 2010;13 (2):12-15. PMID 19888870. doi:10.2350/09-07-0680-CR.1

22. Adam S, Coetzee M, Honey EM. Pena-Shokeir syndrome: current management strategies and palliative care. Appl Clin Genet. 2018;11:111-120. PMID 30498368. doi:10.2147/TACG.S154643

23. Ho NC. Monozygotic twins with fetal akinesia: the importance of clinicopathological work-up in predicting risks of recurrence. Neuropediatrics. 2000;31(5):252-256. PMID 11204282. doi:10. 1055/s-2000-9238

24. King JA, Gardner V, Chen H, Blackburn W. Neu-Laxova syndrome: pathological evaluation of a fetus a review of the literature. Pediatr Pathol Lab Med. 1995;15(1):57-79. PMID 873659. doi: $10.3109 / 15513819509026940$

25. Mau U, Kendziorra H, Kaiser P, Enders H. Restrictive dermopathy: report and review. Am J Med Genet. 1997;71(2):179-185. doi:10.1002/(sici)1096-8628(19970808)71:2<179:aid-ajmg11>3. $0 . \mathrm{co} ; 2-\mathrm{b}$

26. Witt DR, Hayden MR, Holbrook KA, Dale BA, Baldwin VJ, Yaylor GP. Restrictive dermopathy; a newly recognized autosomal recessive skin dysplasia. Am J Med Genet. 1986;24 (4):631-648. PMID 2426945. doi:10.1002/ajmg.1320240408

27. Dane B, Dane C, Aksoy F, Cetin A, Yayla M. Arthrogryposis multiplex congenital analysis of twelve cases. Clin Exp Obstet Gynecol. 2009;36(4):259-262. PMID 20101863.

28. Colpaert C, Bogers J, Hertveldt K, Loquet P, Dumon J, Willems P. Limb-body wall complex: 4 new cases illustrating the importance of examining placenta and umbilical cord. Pathol Res Pract. 2000;196(11):783-790. PMID 11186178.

29. Aguirre-Pascual E, Epelman M, Johnson AM, Chauvin NA, Coleman BG, Victoria T. Prenatal MRI evaluation of limb-body wall complex. Pediatr Radiol. 2014;44(11):1412-1420. doi:10. 1007/s00247-014-3026-9

30. Iqbal CW, Derderian SC, Cheng Y, Lee H, Hirose S. Amniotic band syndrome: a single-institutional experience. Fetal Diagn Ther. 2015;37(1):1-5. doi:10.1159/000358301

31. Viscarello RR, Ferguson DD, Nores J, Hobbins JC. Limb-body wall complex associated with cocaine abuse: further evidence of cocaine's teratogenicity. Obstet Gynecol. 1992;80(3 Pt 2):253-256. PMID 1386662.

32. Ginsberg NE, Cadkin A, Strom C. Prenatal diagnosis of body stalk anomaly in the first trimester of pregnancy. Ultrasound Obstet Gynecol. 1997;10(6):419-421. PMID 947329. doi:10.10 46/j.1469-0705.1997.10060419.x

33. Negishi H, Yaegashi M, Kato EH, Yamada H, Okuyama K, Fujimoto S. Prenatal diagnosis of limb-body wall complex. J Reprod Med. 1998;43(8):659-664. PMID 9749415.

34. Daskalakis GJ, Nicolaides KH. Monozygotic twins discordant for body stalk anomaly. Ultrasound Obstet Gynecol. 2002;20(1):79-81. PMID 12100424. doi:10.1046/j.1469-0705.2002.00631.w

35. Jidha TD, Wiakjira T, Mekonnen T. Body stalk anomaly presenting as an emergency in Ethiopia: a case report. J Med Case Rep. 2020;14(1):205. doi:10.1186/s13256-13256-020-02509-3

36. Gajzer DC, Hirzel AC, Saigal G, Rojas CP, Rodriguez MM. Possible genetic origin of limb-body wall complex. Fetal Pediatr Pathol. 2015;34(4):257-270. PMID 26111189. doi:10. 3109/15513815

37. Smrcek JM, Germer U, Krokowski M, et al. Prenatal ultrasound diagnosis and management of body stalk anomaly: analysis of nine singleton and two multiple pregnancies. Ultrasound Obstet Gynecol. 2003;21(4):322-328. PMID 12858309. doi:10.1002/ uog. 153 
38. Türkyilmaz G, Avci S, Sivrikoz T, et al. Prenatal diagnosis and management of ectopia cordis: varied presentation spectrum. Fetal Pediatr Pathol. 2019;38(2):127-137. PMID 30600745. doi:10.1080/15513815.2018.1556367

39. Sornes T. Short umbilical cord as a cause of fetal distress. Acta Obstet Gynecol Scand. 1989;68(7):609-611. PMID 2631528. doi:10.31019/00016348909013279

40. Anath CV, Oyelese Y, Yeo L, Pradhan A, Vintzileos AM. Placental abruption in the United States, 1979 through 2001: temporal trends and potential determinants. Am J Obstet Gynecol. 2005;192(1):191-198. PMID 15672024. doi:10.1016/j. ajog.2004.05087

41. Georgiais A, Keski-Nisula L, Harju M, et al. Umbilical cord length in singleton gestations: a Finnish population-based retrospective register study. Placenta. 2014;35(4):275-290. PMID 24560495. doi:10.1016/j.placenta.2014.02001

42. Wendel MP, Shanekel KL, Magann EF. Uterine inversion. A review of a life-threatening obstetrical emergency. Obstet Gynecol Surv. 2018;73(7):411-417. PMID 30062382. doi:10. 1097/OGX.0000000000000580

43. Iwagaki S, Takahashi Y, Chiaki R, et al. Umbilical cord length affects the efficacy of amnioinfusion for repetitive variable decelerations during labor. J Matern Fetal Neonat Med. 2020;1-5. doi:10.1080/14767058.2020.1712703

44. Yamamoto Y, Aoki S, Oba MS, Seki K, Hirahara F. Short umbilical cord length: reflective of adverse pregnancy outcomes. Clin Exp Obstet Gynecol. 2017;44(2):216-219. PMID 29746025.

45. Solertre L. Three-dimensional multiplanar ultrasound in a limb-body wall complex fetus: clinical evidence for counseling. J Matern Fetal Neonatal Med. 2006;19(2):109-112. PMID 16581607. doi:10.1080/147670504000028840

46. Bijok J, Massalska D, Kuncinska-Chawan A, et al. Complex malformations involving the fetal body wall - definition and classification issues. Prenat Diagn. 2017;37(10):1033-1039. doi:10.1002/pd.5141

47. Sherer DM, Dalloul M, Garza M, Benton L, Abulafia O. Prenatal sonographic diagnosis of acardiac twin embedded within placenta. Ultrasound Obstet Gynecol. 2018;52(1):120-121. PMID 29155482. doi:10.1002/uog.18964

48. Hill LM, DiNofrio DM, Guzick D. Sonographic determination of first trimester umbilical cord length. J Clin Ultrasound. 1994;22 (7):435-438. PMID 7962590. doi:10.1002/jcu.1870220704

49. Collins JH. Ultrasound measurement of umbilical cord length. Am J Obstet Gynecol. 1994;13(11):854.

50. Sherer DM, Dalloul M, Ajayi O, Kheyman M, Sokolvski M, Abulafia O. Prenatal diagnosis of short umbilical cord in a dichorionic twin with normal fetal anatomy. $J$ Clin Ultrasound. 2010;38(2):91-93. PMID 19802888. doi:10.1002/ jcu.20639

51. Ugurlucan FG, Yuskel A. Is complete umbilical cord scanning possible at the second-trimester ultrasound scan? $J$ Clin Ultrasound. 2015;43(4):249-253. doi:10.1002/jcu.22242

52. Gur EB, Gulec ES, Aydogmus S, et al. Can the difference of Doppler indexes at different points of the umbilical cord predict to the umbilical cord length? J Matern Fetal Neonatal Med. 2020;33(5):847-851. PMID 30173592. doi:10.1080/14767 058.2018 .1506440

53. Katsura D, Takahashi Y, Shimizu T, et al. Prenatal measurement of umbilical cord length using magnetic resonance imaging. Eur J Obstet Gynecol Reprod Biol. 2018;231:142-146. PMID 30388608. doi:10.1016/j.ejogrb.2018.10.10.037

54. Ghezzi F, Raio L, Di Naro E, et al. First-trimester sonographic umbilical cord diameter and the growth of the human embryo. Ultrasound Obstet Gynecol. 2001;18(4):348-351. doi:10.1046/ j.0960-7692.2001.00100507.x
55. Ghezzi F, Raio L, Di Naro E, Franchi M, Buttarelli M, Schneider H. First-trimester umbilical cord diameter: a novel marker of fetal aneuploidy. Ultrasound Obstet Gynecol. 2002;19 (3):235-239. PMID 11936081. doi:10.1046/j.1469-0705.2002. 00650.x

56. Axt-Fliedner R, Schwarze A, Kreiselmaier P, Krapp M, Smrcek JD, Diedrich K. Umbilical cord diameter ar 11-14 weeks of gestation: relationship to nuchal translucency, ductus venosus blood flow and chromosomal defects. Fetal Diagn Ther. 2006;21(4):390-395. doi:10.1159/000092472

57. Weissman A, Jakobi P, Bronshtein M, Goldstein I. Sonographic measurements of the umbilical cord and vessels during normal pregnancies. J Ultrasound Med. 1994;13(1):11-14. PMID 7636947. doi:10.7863/jum.1994.13.1.11

58. Debebe SK, Cahill LS, Kingdom JC, et al. Wharton's jelly area and its association with placental morphology and pathology. Placenta. 2020;94:34-38. PMID 32421532.

59. Ghezzi F, Raio L, Di Naro E, Franch M, Balestreri D, D'Addario V. Nomogram of Wharton's jelly as depicted in the sonographic cross-section of the umbilical cord. Ultrasound Obstet Gynecol. 2001;18(2):121-125. doi:10.1046/j.1469-0705. 2001.00468.x

60. Raio L, Ghezzi F, Di Naro E, et al. Prenatal diagnosis of a lean umbilical cord: a simple marker for the fetus at risk of being small for gestational age at birth. Ultrasound Obstet Gynecol. 1999;13 (3):176-180. doi:10.1046/j.1469-0705.1999.13030176.x

61. Raio LG, Di Naro E, Duwe DG, Cromi A, Scheider H, Schneider H. Umbilical cord morphologic characteristics and umbilical artery Doppler parameters in intrauterine growth-restricted fetuses. J Ultrasound Med. 2003;22 (12):1341-1347. doi:10.7863/jum.2003.22.12.1341

62. Cromi A, Ghezzi F, Di Naro E, Siesto G, Beraminin V, Raio L. Large cross-sectional of the umbilical cord as a predictor of fetal macrosomia. Ultrasound Obstet Gynecol. 2007;30(6):861-866. doi:10.1002/uog.5183

63. Raio L, Ghezzi F, Di Naro E, Franchi M, Brühwiler H, Lüscher KP. Prenatal assessment of Wharton's jelly in umbilical cords with single artery. Ultrasound Obstet Gynecol. 1999;14 (1):42-46. doi:10.1046/j.1469-0705.1999.14010042.x

64. Sherer DM, Houry-Collado F, Dalloul M, et al. Recurrent antepartum compression of a single artery double nuchal cord necessitating Cesarean delivery. Am J Perinatol. 2005;22(8):437-440. doi:10.1055/s-2005-916286

65. Cromi A, Ghezzi F, Dürig P, Di Naro E, Raio L. Sonographic umbilical cord morphometry and coiling patterns in twin-twin transfusion syndrome. Prenat Diagn. 2005;25(9):851-855. PMID 16170861. doi:10.1002/pd.1273

66. Ulberg U, Sandstedt B, Limgman G. Hyrtl's anastomosis, the only connection between the two umbilical arteries. A study in full term placentas from AGA infants with normal umbilical artery blood flow. Acta Obstet Gynecol Scand. 2001;80(1):1-6. PMID 11167180. doi:10.1034/j.1600-0412.2001.800101.x

67. Ulberg U, Lingman G, Ekman-Orderberg G, Sandstedt B. Hyrtl's anastomosis is normally developed in placentas from small for gestational age infants. Acta Obstet Gynecol Scand. 2003;82 (8):716-721. PMID 12848642. doi:10.1034/j.1600-0412.20 03.00161.x

68. Gordon Z, Eytan O, Jaffa AJ, Elad D. Hemodynamic analysis of Hyrtl anastomosis in human placenta. Am J Physiol Regul Integr Comp Physiol. 2007;292(2):R977-R982. PMID 17038439. doi:10.1152/ajpregu.004.2006.

69. Bhutia KL, Sengupta R, Upreti B, Tamang BK. Pregnancyinduced hypertension is associated with altered anatomical patterns of Hyrtl's anastomosis. Anat Rec (Hoboken). 2014;297 (5):819-825. PMID 24592334. doi:10.1002/ar.22894. 
70. Donepudi RV, Moise KJ. Intrauterine transfusion complicated by umbilical artery thrombosis. Case Rep Obstet Gynecol. 2019;2019:5952326.

71. Rembouskos G, Cicero S, Longo D, Sacchini C, Nicolaides KH. Single umbilical artery at 11-14 weeks' gestation: relation to chromosomal defects. Ultrasound Obstet Gynecol. 2003;22 (6):567-570. PMID 14689527. doi:10.1002/uog.901

72. Blazer D, Sujov P, Escholi Z, Itai BH, Bronshtein M. Single umbilical artery - right or left? Does it matter? Prenat Diagn. 1997;17(1):5-8. PMID 9021822. doi:10.1002/(sici)1097-0223(199701)17:1<5::aid-pd>3.0.co;2-4

73. Friebe-Hoffmann U, Hiltmann A, Friedl TWP, et al. Prenatally diagnosed single umbilical artery (SUA) - retrospective analysis of 1169 fetuses. Ultraschall Med. 2019;40(2):221-229. PMID 29590672. doi:10.1055/s-0043-1234

74. Gurvitz G, Walfish A, Beharier O, Sheiner E. Isolated single umbilical artery is an independent risk factors for perinatal mortality and adverse outcomes in term neonates. Arch Gynecol. 2016;294(5):931-935. PMID 27048509. doi:10.1007/s00404016-4088-8.

75. Sepulveda W, Peek MJ, Hassan J, Hollingsworth J. Umbilical vein to artery ratio in fetuses with single umbilical artery. Ultrasound Obstet Gynecol. 1996;8(1):23-26. PMID 8843614. doi:10.1046/j.1469-0705.1996.08010023.x

76. Painter D, Russell P. Four-vessel umbilical cord associated with multiple congenital anomalies. Obstet Gynecol. 1977;50(4):5 05-507. PMID 904818.

77. Karatza A, Tsamandas A, Varvarigou A, Davlouros P, Pavlou V, Mantagos S. Supernumerary umbilical vein in a hydropic neonate with hypertrophic cardiomyopathy. Fetal Pediatr Pathol. 2011;30 (3):173-176. PMID 21355676

78. Puvabanditsin S, Garrow E, Bhatt M, et al. Four-vessel cord associated with multiple congenital anomalies: a case report and literature review. Fetal Pediatr Pathol. 2011;30(2):98-105. PMID 21391749. doi:10.3109/15513815.2010.524687

79. Panda S, Jah V, Khonglah Y, Dey B. A multivessel umbilical cord with a single umbilical artery. J Clin Diagn Res. 2013;7 (7):1453-1454. PMID 23998091. doi:10.7860/JCDR/2013/5220. 3153

80. Pérez-Cosio C, Sheiner E, Abramowicz JS. Four vessel umbilical cord not always a dire prognosis. $J$ Ultrasound Med. 2008;27:1389-1391. doi:10.7863/jum.2008.27.9.1389

81. Schimmel MS, Eidelman AI. Supernumerary umbilical vein resulting in a four-vessel umbilical cord. Am J Perinatol. 1998;15:299-301. doi:10.1055/s-2007-993947

82. Du W, Yuan Q, Li Z, Li Y. Three umbilical arteries resulting in four-vessel umbilical cord in a stillbirth. Int J Clin Exp Med. 2015;8(3):4682-4685. PMID 26064402.

83. Cohen HL, Shapiro ML, Haller JO, Schwartz D. The multivessel umbilical cord: an antenatal indicator of possible conjoined twinning. J Clin Ultrasound. 1992;20(4):278-282. doi:10.1002/ jcu. 1870200409

84. Hecht C, Baumann M, Spinelli M, Tripple M, Raio L. Umbilical cord in conjoined twins: prenatal imaging and anatomopathological aspects. Ultrasound Obstet Gynecol. 2019;53:269-273. doi:10.1002/uog.20095

85. Thomas K, Dargent JL, Brans A, Flippidis M. Prenatal diagnosis of forked umbilical cord in monochorionic diamniotic pregnancy. Ultrasound Obstet Gynecol. 2006;28:343-346. doi:10.1002/uog.2833

86. Fraser RB, Liston RM, Thompson DL, Wright JR. Monoamniotic twins delivered liveborn with forked umbilical cord. Pediatr Pathol Lab Med. 1997;17:639-644. doi:10.1080/15513819709168742

87. Guo Y, Sun Y, Yang H. Growth discordance of monoamniotic twin because of difference of cords diameter in forked umbilical cord: case report. Medicine (Baltimore). 2017;96(37):e8042. PMID 28906394.
88. Frisch L, Groisman G, Hallak M. First trimester diagnosis of forked cord in monoamniotic twin pregnancy. Placenta. 2011;32 (12):1057-1059. doi:10.1016/j.placenta.2011.09.008

89. Weston PJ, Ives EJ, Honore RL, Lees GM, Sinclair DB, Schiff D. Monochorionic diamniotic minimally conjoined twins: a case report. Am J Med Genet. 1990;37(4):558-561. PMID 2260608. doi:10.1002/amjg.1320370428

90. Rehder H, Schoner K, Kluge B, Louwen F, Schwinger E, Neesen J. Klinefelter twins presenting with discordant aneuploidies, acardia, forked umbilical cord with different gonadal sex despite monozygosity. Prenat Diagn. 2012;32(2):173-179. PMID 2241892. doi: $10.1002 /$ pd.2928

91. Strong TH, Jarles DL, Vega JS, Feldman DB. The umbilical coiling index. Am J Obstet Gynecol. 1994;170(1):29-32. doi:10.1016/S0002-9378(94)70378-7

92. Strong TH, Manriquez-Gilpin MP, Gilpin BG. Umbilical coiling and nuchal entanglement. J Matern Fetal Med. 1996;5(6):359-361.

93. Rana J, Ebert GA, Kappy KA. Adverse perinatal outcome in patients with an abnormal umbilical coiling index. Obstet Gynecol. 1995;85 (4):573-577. PMID 7898836. doi:10.1016/0029-7844(94)00435-G.

94. Ernst LM, Minturn L, Huang MH, Curry E, Su EJ. Gross patterns of umbilical coiling: correlations with placental histology and stillbirth. Placenta. 2013;34(7):583-588. PMID 23642640. doi:10.1016/j.placenta.2013.04.002

95. Machin GA, Ackerman J, Gilbert-Barness E. Abnormal umbilical cord coiling is associated with adverse perinatal outcomes. Pediatr Dev Pathol. 2000;3(5):462-471. PMID 10890931. doi:10.1007/s100240010103

96. Ayala NK, Ernst LM, Miller ES. Is umbilical coiling determined? J Perinatol. 2018;38(6):653-657. PMID 29467518. doi:10.1038/ s41372-018-0078

97. Dolkart LA, Reimers FT, Kuonen CA. Discordant umbilical arteries: ultrasonographic and Doppler analysis. Obstet Gynecol. 1992;79:59-63.

98. Petrikovski B, Schneider E. Prenatal diagnosis and clinical significance of hypoplastic umbilical artery. Prenat Diagn. 1996;16 (10):938-940. doi:10.1002/(SICI)1097-0223(199610)16:10<938:: AID-PD964>3.0.CO;2-S

99. Raio L, Ghezzi F, Di Naro E, Gomez R, Saile G, Brunhwiler H. The clinical significance of antenatal detection of discordant umbilical arteries. Obstet Gynecol. 1998;91:86-91. doi:10.1016/ s0029-7844(97)00543-7

100. Predanic M, Perni SC. Antenatal assessment of discordant umbilical arteries n singleton pregnancies. Croat Med J. 2006;47 (5):701-708. PMID 17042061.

101. Laberke PJ, Deubler G. Sudden intrauterine death associated with furcate insertion of the umbilical cord. Int $J$ Legal Med. 2009;123:509-512. doi:10.1007/s00414-008-295-6

102. Cohen B, Wilson M, Cohen A, Yum M. Prenatal diagnosis of a furcate placenta. Obstet Gynecol. 2020;135(4):960-963. doi:10.1097/AOG.0000000000003744

103. Lamale-Smith LM, Snuttjer MJ, Harper TC. Furcate umbilical cord insertion: disparate outcomes of a rare obstetrical findings. A case report. J Reprod Med. 2015;60(7-8):365-368.

104. Fujita Y, Yumoto Y, Kato K. Prenatal diagnosis of abnormal umbilical cord insertion: a rare case of furcate insertion. JMed Ultrasound (2001). 2017;44(2):203-205. doi:10.1007/s10396-016-0758-1

105. Esakoff TF, Cheng YW, Snowden JM, Tran SH, Shaffer BL, Caughey AB. Velamentous cord insertion: is it associated with adverse perinatal outcomes? J Matern Fetal Neonatal Med. 2015;28(4):409-412. doi:10.3109/14767058.2014.918098

106. Ebbing A, Kiserud T, Johnson SL, Albrechtsen S, Rasmussen S. Prevalence, risk factors and outcomes of velamentous and marginal cord insertions: a population-based study of 634,741 pregnancies. PLosS One. 2013;8(7):e70380. PMID 23936197. doi:10.1371/journal.pone.0070380. 
107. Sinkin JA, Craig WY, Jones M, Pintette MG, Wax JR. Perinatal outcomes associated with isolated velamentous cord insertion in singleton and twin pregnancies. J Ultrasound Med. 2018;37 (2):471-478. PMID 28850682. doi:10.1002/jum.14357

108. Heinonen S, Ryynannen M, Kirkinen P, Saarikoski S. Perinatal diagnostic evaluation of velamentous umbilical cord insertion: clinical, Doppler, and ultrasonic findings. Obstet Gynecol. 1996;87(1):112-117. doi:10.1016/0029-7844(95)00339-8

109. Buchanan-Hughes A, Bobrowska A, Vistintin C, Attilakos G, John M. Velamentous cord insertion: results from a rapid review of incidence, risk factors, adverse outcomes and screening. Syst Rev. 2020;9(1):147. PMID 32576295. doi:10.1186/s13643-02001355-0

110. Monteagudo A, Sfakianaki AK, Timor-Trisch IE. Velamentous insertion of the cord in the first trimester. Ultrasound Obstet Gynecol. 2000;16(5):498-499. doi:10.1046/j.1469-0705.2000.00282x

111. Derisbourg S, Boulay A, Lamy C, et al. First trimester ultrasound prediction of velamentous cord insertions: a prospective study. J Matern Fetal Neonatal Med. 2019:34:1-7. PMID 31558066. doi:10.1080/14767058.2019.167097

112. Sepulveda W, Rojas I, Robert JA, Scnapp C, Alcade JL. Prenatal detection of velamentous insertion of the umbilical cord: a prospective color Doppler study. Ultrasound Obstet Gynecol. 2003;21(6):564-569. PMID 12808673. doi:10.1002/uog.132

113. Sepulveda W. Velamentous insertion of the umbilical cord: a first-trimester sonographic screening study. J Ultrasound Med. 2006;25(8):963-8;quiz 970. doi:10.7863/jum.2006.25.8.963

114. Hasegawa J, Matsuoka R, Ichizuka K, Sekizawa A, Okai T. Velamentous cord insertion: significance of prenatal detection to predict perinatal complications. Taiwan $J$ Obstet Gynecol. 2006;45(1):21-25. doi:10.1016/S1028-4559(09)60185-6

115. Nomiyama M, Toyota $\mathrm{Y}$, Kawano H. Antenatal diagnosis of velamentous umbilical cord and vasa previa with color Doppler imaging. Ultrasound Obstet Gynecol. 1998;12(6):426-429. doi:10.1046/j.1469-0705.1998.1206042.x

116. Lee HM, Lee SW, Park MK, et al. Clinical significance of velamentous cord insertion prenatally diagnosed in twin pregnancy. J Clin Med. 2021;10(4):572. PMID 33546368. doi: $10.3390 / \mathrm{jcm} 10040572$

117. Fries MH, Goldstein RB, Kilpatrick SJ, Golbus MS, Callen PW, Filly RA. The role of velamentous cord insertion on the etiology of twin-twin transfusion syndrome. Obstet Gynecol. 1993;81 (4):69-74.

118. Costa-Castro T, De Villiers S, Montenegro N, Oepkes D, Matias A, Lopirore E. Velamentous cord insertion in monochorionic twins with or without twin-twin transfusion syndrome: does it matter? Placenta. 2013;34(11):10530-10538. PMID 24011780. doi:10.1016/j.placenta.2013.08.009

119. Yonenati N, Ishii K, Kawamura H, Mabuchi A, Hayashi S, Mitsuda N. Significance of velamentous cord insertion for twin-twin transfusion syndrome. Fetal Diagn Ther. 2015;38 (4):276-281. PMID 25925425. doi:10.1159/000381639

120. Lopriore E, Suetres M, Middledorp JM, Oepkes D, Walther FJ, Vandenbussche FPHA. Velamentous cord insertion and unequal placental territories in monochorionic twins with and without twin-to-twin transfusion syndrome. Am $J$ Obstet Gynecol. 2007;196(2):159.e1-5. doi:10.1016/j.acog.2006.10.865

121. Couke I, Mourad Tawfic N, Deprest J, De Catte L, Devlieger R, Lewi L. Does site of cord insertion increase risk of adverse outcome, twin-to-twin transfusion syndrome and discordant growth in monochorionic twin pregnancy. Ultrasound Obstet Gynecol. 2018;52 (3):385-389. PMID 29024208. doi:10.1002/uog.18926

122. Kalafat E, Thilaganathan B, Papageorghiou A, Bhide A, Khalil A. Significance of placental cord insertion site in twin gestations. Ultrasound Obstet Gynecol. 2018;52(3):378-384. doi:10.1002/ uog. 18914
123. Lin D, Fan D, Wu S, et al. Role of velamentous cord insertion in monochorionic twin pregnancies: a PRISMA-compliant systematic review and meta-analysis of observational studies. $J$ Matern Fetal Neonatal Med. 2020;33(14):2377-2386. PMID 30458694. doi:10.1080/14767058.2018.1551350

124. Sherer DM, Abramowicz JS, Sinkin RA, Metlay LA, Geilfuss CJ, Woods JR. Marked growth discordancy in three sets of twins associated with velamentous insertion of the umbilical cord of the smaller twin. J Matern Fetal Med. 1993;2:165. doi:10.3109/ 14767059309017335

125. Gulersen M, Miller RS, Rochelson B. An unusual velamentous cord insertion into the intertwin dividing membrane. Am J Obstet Gynecol. 2020;223(5):758-759. doi:10.1016/j.ajog.2020.04.008

126. Nelson LH, Fishburne JI, Stearns BR. Ultrasonographic description of succenturiate lobe. Obstet Gynecol. 1977;49(1 suppl):79-80.

127. Spirt BA, Kagan EH, Gordon LP, Massad LS. Antepartum diagnosis of a succenturiate lobe: sonographic and pathologic correlation. J Clin Ultrasound. 1981;9(3):139-140. doi:10.1002/ jcu. 1870090309

128. Anguaco TL, Boyd CM, Marks SR, Quirk JG, Galwas B. Sonographic diagnosis of the bilobate placenta. J Ultrasound Med. 1986;5(11):672-674. doi:10.7863/jum.1986.5.11.672

129. Hata K, Hata T, Aoki S, Takamori H, Takamiya O, Kitao M. Succenturiate placenta diagnosed by ultrasound. Gynecol Obstet Invest. 1988;25(4):273-276. doi:10.1159/000293798

130. Chihara H, Otsubo Y, Ohta Y, Araki T. Prenatal diagnosis of succenturiate lobe by ultrasonography and color Doppler imaging. Arch Gynecol Obstet. 2000;263(3):137-138. doi:10.10 07/s004040050013

131. Oyelese KO, Turner M, Lees C, Campbell S. Vasa previa: and avoidable obstetric tragedy. Obstet Gynecol Surv. 1999;54 (2):138-145. doi:10.1097/00006254-199902000-00024

132. Oyelese KO, Schärzler P, Coates S, Sansui FA, Hamid R, Campbell S. A strategy for reducing the mortality rate from vasa previa using transvaginal sonography with color Doppler. Ultrasound Obstet Gynecol. 1998;12(6):434-438. doi:10.1046/ j.1469-0705.1998.12060434.x

133. Oyelese Y, Catanzarite V, Prefumo F, et al. Vasa previa: the impact of prenatal diagnosis on outcomes. Obstet Gynecol. 2004;103(5 Pt 1):937-942. doi:10.1097/01.AOG.0000123245.48645.98

134. Baulies S, Maiz N, Muñoz A, Torrents M, Echevarría MS, Serra B. Prenatal ultrasound diagnosis of vasa previa and analysis of risk factors. Prenat Diagn. 2007;27(7):595-599. doi:10.1002/pd.1753

135. Zhang W, Geris S, Beta J, Nicolaides KH, Akolekar R, Akolekar R. Prevention of stillbirth: impact of two-stage screening for vasa previa. Ultrasound Obstet Gynecol. 2020;55 (5):605-612. doi:10.1002/uog.21953

136. Yang M, Zheng Y, Li M, et al. Clinical features of velamentous umbilical cord insertion and vasa previa: a retrospective analysis based on 501 cases. Medicine (Baltimore). 2020;99(51):e23166. PMID 33371061. doi:10.1097/MD.0000000000023166

137. Pavalagantharajah S, Villani LA, DSouza R. Vasa previa and associated risk factors: as systematic review and meta-analysis. Am J Obstet Gynecol MFM. 2020;2(3):100117. doi:10.1016/j. ajogmf.2020.100117

138. Ruiter L, Kok N, Limpens J, et al. Systematic review of accuracy of ultrasound in the diagnosis of vasa previa. Ultrasound Obstet Gynecol. 2015;45(5):516-522. doi:10.1002/uog.14752

139. Rebarber A, Dolin C, Fox NS, Klauser CK, Saltzman DH, Roman AS. Natural history of vasa previa across gestation using a screening protocol. J Ultrasound Med. 2014;33 (1):141-147. PMID 24371109. doi:10.7863/ultra.33.1.141

140. Ranzini AC, Oyelese Y. How to screen for vasa previa. Ultrasound Obstet Gynecol. 2020;57(5):720-725. doi:10.1002/ uog. 23520 
141. Bohiltea RE, Cirsroiu MM, Ciuvica AI, et al. Velamentous insertion of umbilical cord with vasa praevia: case series and literature review. J Med Life. 2016;9(2):126-129. PMID 27453740.

142. Sullivan EA, Javid N, Duncombe G, et al. Vasa previa diagnosis, clinical practice, and outcomes in Australia. Obstet Gynecol. 2017;130(3):591-598. doi:10.1097/AOG.0000000000 002198

143. Melcer Y, Maymon R, Jauniaux E. Vasa previa: prenatal diagnosis and management. Curr Opin Obstet Gynecol. 2018;30 (6):385-391. doi:10.1097/GCO.0000000000000478

144. Lijoi AF, Brady J. Vasa previa diagnosis and management. $J$ Am Board Fam Pract. 2003;16(6):543-548. PMID 14963081. doi:10. 3122/jabfm.16.6.543

145. Catanzarite V, Maida C, Thjomas W, Mendoza A, Stanco L, Piacquadio KM. Prenatal sonographic diagnosis of vasa previa: ultrasound findings and obstetric outcome in ten cases. Ultrasound Obstet Gynecol. 2001;18(2):109-115. doi:10.1046/ j.1469-0705.2001.00448.x

146. Kulkarni A, Powel J, Aziz M, et al. Vasa Previa: prenatal diagnosis and outcomes: thirty-five cases from a single maternal-fetal medicine practice. J Ultrasound Med. 2018;37(4):1017-1024. doi:10.1002/jum.14452

147. Klahr R, Fox NS, Zafman K, Hill MB, Connolly CT, Rebarber A. Frequency of spontaneous resolution of vasa previa with advancing gestational age. Am J Obstet Gynecol. 2019;221(6):646.e1646.e7. PMID 31233708. doi:10.1016/j.ajog.2019.06.040

148. Sepulveda W, Rojas I, Robert JA, Schnapp C, Alcade JL. Prenatal detection of velamentous insertion of the umbilical cord: a prospective color Doppler ultrasound study. Ultrasound Obstet Gynecol. 2003;21(6):564-569. PMID 12808673. doi:10.1002/ uog. 132

149. American College of Obstetricians and Gynecologists. Medically indicated late-preterm and early term deliveries. ACOG Committee opinion no. 764. February 2019. Obstet Gynecol. 2013;121:908-910.

150. Sinkey RG, Odibo AO, Dashe JS; Society for Maternal-Fetal Medicine (SMFM) Publications Committee. Diagnosis and management of vasa previa. Am J Obstet Gynecol. 2015;213:615-619. doi:10.1016/j.ajog.2015.08.031

151. Sinkey RG, Odibo AO. Vasa previa screening strategies: decision and cost-effectiveness analysis. Ultrasound Obstet Gynecol. 2018;52(4):522-529. doi:10.1002/uog.19098

152. Melcer Y, Pekar-Zlotin N, Wolf B, et al. Is scanning for vasa previa important for singleton pregnancies that started as multiple conceptions? Eur J Obstet Gynecol Reprod Biol. 2019;238:100-103. PMID 31128531. doi:10.1016/j.ejogrb.20 19.05.018

153. Kikuchi A, Uemura R, Serikawa T, Takakuwa K, Tanaka K. Clinical significance of magnetic resonance imaging in prenatal diagnosis of vasa previa in a woman with bilobed placentas. J Obstet Gynaecol Res. 2011;37(1):75-78. doi:10.1111/j.14470756.2010.01308.x

154. Oyelese Y, Chavez MR, Yeo L, et al. Three-dimensional sonographic diagnosis of vasa previa. Ultrasound Obstet Gynecol. 2004;24(2):211-215. doi:10.1002/uog.1097

155. Jauniaux E, Melcer Y, Maymon R. Prenatal diagnosis and management of vasa previa in twin pregnancies: a case series and systematic review. Am J Obstet Gynecol. 2017;216(6):568-575. PMID 28153653. doi:10.1016/j.ajog.2017.01.029

156. Oyelese Y, Spong C, Fernandez MA, McLaren RA. Second trimester low-lying placenta and in-vitro fertilization? Exclude vasa previa. J Matern Fetal Med. 2000;9:370-372.

157. Isotton AL, Salazar CC, Peralta CFA, Abdalla JML, Vettorazzi J. In vitro fertilization and vasa previa: a report of two cases. Rev Bras Ginecol Obstet. 2019;41(5):348-351. doi:10.1055/s-00391683354
158. Nkwabong E, Njikam F, Kalla G. Outcome of pregnancies with marginal umbilical cord insertion. J Matern Fetal Neonat Med. 2021;34(7):1133-1137. PMID 31164018. doi:10.1080/147670 58.2019.1628206

159. Christopher CR, Spinelli A, Collins ML. Ultrasonic detection of "hourglass membranes" with funic presentation. Obstet Gynecol. 1979;54(1):130-132. doi:10.1097/000062250-19790 7000-00031

160. Vintzileos AM, Nochimson DJ, Lillo NL, Tohan N. Ultrasonic diagnosis of funic presentation. J Clin Ultrasound. 1983;11 (9):520-521. doi:10.1002/jcu.1870110913

161. Oyelese Y, Yeo L, Kinzler W, Smulian J, Vintzileos AM. Persistent funic presentation resulting from marginal cord insertion into a low-lying placenta. Ultrasound Obstet Gynecol. 2004;24(6):692-693. PMID 15386613. doi:10.1002/uog.1069

162. Ezra Y, Strasberg SR, Farine D. Does cord presentation on ultrasound predict cord prolapse? Gynecol Obstet Invest. 2003;56:6-9. doi:10.1159/000072323

163. Raga F, Osborne N, Ballester M, Bonilla-Musoles F. Color flow Doppler: a useful instrument in the diagnosis of funic presentation. J Natl Med Assoc. 1996;88(2):94-96.

164. Jo YS, Kim MJ, Lee GSR, Kim SJ. A large amniocele with protruded umbilical cord diagnosed by $3 \mathrm{D}$ ultrasound. Int $J$ Med Sci. 2012;9(5):387-390. doi:10.7150/ijms.3383

165. Zhu Y, Beejadhursing R, Liu Y. 10 cases of umbilical cord thrombosis in the third trimester. Arch Gynecol Obstet. 2021;304:59-64. PMID 33389094. doi:10.1007/s00404-02005910-x

166. Lutfallah F, Oufkir N, Markou GA, Frimigacci D, Poncelet C. A case of umbilical artery thrombosis in the third trimester of pregnancy. Am J Case Rep. 2018;19:72-75. PMID 29348396. doi:10.12659/ajcr.906859

167. Shilling C, Walsh C, Downey P, Mooney E. Umbilical artery thrombosis is a rare but clinically important finding: a series of 7 cases with clinical outcomes. Pediatr Dev Pathol. 2014;17 (2):89-93. PMID 24559159. doi:10.2350/13-11-1407-OA1

168. Sato Y, Benirschke K. Umbilical arterial thrombosis with vascular wall necrosis: clinicopathologic findings of 11 cases. Placenta. 2006;27(6-7):715-718. PMID 16112729. doi:10.1016/j.placenta. 2005.05 .006

169. Klaitsch P, Haeusler M, Karpf E, Schlembach D, Lang U. Spontaneous intrauterine umbilical artery thrombosis leading to severe fetal growth restriction. Placenta. 2008;29(4):374-377. PMID 18289672. doi:10.1016/j.plaxenta.2008.01.004

170. De Olivera GH, de Moraes Dias C, Vaz-Oliani DC, Oliani AH. Intrauterine thrombosis of umbilical artery - case report. San Paulo Med J. 2016;134(4):355-358. PMID 27276083. doi:10.15 90/1616-3180.2016.00081203

171. Li H, Wu Q, Wei W, Lin X, Zhang X. Umbilical artery thrombosis: two case reports. Medicine (Baltimore). 2019;98(48): e18170. PMID 31770267. doi:10.1097/MD000000000008170

172. Sherer DM, Dalloul M, Guerra R, Bahamon C, Abulafia O. Prenatal sonographic depiction of large intra-amniotic vein thrombosis. J Ultrasound Med. 2018;37(11):2733-2734. PMID 29656547. doi:10.1002/jum. 14620

173. Abrams SK, Callen PW, Filly RA. Umbilical vein thrombosis: sonographic detection in utero. J Ultrasound Med. 1985;4 (6):283-285. doi:10.7863/jum.1985.4.6.283

174. Minakami H, Akahori A, Sakurai A, Yamauchi A, Sato I. Umbilical vein thrombosis as a possible cause of perinatal morbidity or mortality: report of two cases. J Obstet Gynaecol Res. 2001;27(2):97-101. PMID 11396646. doi:10.1111/j.1447-0756. 2001.tb01228.x

175. White SP, Kofinas A. Prenatal diagnosis and management of umbilical vein varix. J Ultrasound Med. 1994;13:992-994. doi:10.7863/jum.1994.13.12.992 
176. Kanenshi H, Akahori A, Sakurai S, Yamauchi A, Sato I. Umbilical vein thrombosis as a possible cause of perinatal morbidity or mortality: report of two cases. J Obstet Gynaecol Res. 2001;27:97-101. doi:10.1111/j.1447-0756.2001.tb01228.x

177. Di Pasquo E, Kuleva M, O’Gorman N, Ville Y, Salomon LJ. Fetal intra-abdominal umbilical vein varix: a retrospective cohort study, systematic review of the literature and meta-analysis. Ultrasound Obstet Gynecol. 2018;51(5):580-585. doi:10.1002/uog.18895

178. Matsumoto Y, Yanai A, Kamei S, Yamaguchi A, Nakamine H, Fujita K. A case report of umbilical vein varix with thrombosis: prenatal ultrasonographic diagnosis and management. Case Rep Obstet Gynecol. 2019;2019:7154560. PMID 31467748. doi:10.11 $155 / 2019 / 7154560$

179. Schröcksnadel H, Holböck E, Mitterschiffthalet G, Tötsch M, Daount O. Thrombotic occlusion of an umbilical vein varix causing fetal death. Arch Gynecol Obstet. 1991;248(4):213-215. PMID 1898126. doi:10.1007/BF02390361

180. Jackson J, Castro E, Belfort M, Shamsirshaz AA, Nassr A, Espinoza J. Massive extra-abdominal umbilical vein varix: a case report. Fetal Diagn Ther. 2021;48(2):158-162. doi:10.11 59/000512490

181. Cassidy-Vu L, Clark S, Cuka N. Extra-abdominal umbilical vein varix in a newborn. BMJ Case Rep. 2019;12(5):e227424. PMID 31061189. doi:10.1136/bcr-2018-227424

182. Io S, Kondoh E, Iemura $\mathrm{Y}$, et al. Severe fetal anemia as a consequence of extra-abdominal umbilical vein varix: a case report and review of the literature. Congenit Anom (Kyoto). 2020;61(1):4-8. PMID 33099808. doi:10.1111/cga12397

183. Beraud E, Rozel C, Milon J, Darnault P. Umbilical vein varix: importance of ante- and post-natal monitoring by ultrasound. Diagn Interv Imaging. 2015;96(1):21-26. PMID 24631035. doi:10.1016/j.diii.2014.01.009

184. Sepulveda W, Mackenna A, Sancjez J, Corral E, Carstens E. Fetal prognosis in varix on the intrafetal umbilical vein. $J$ Ultrasound Med. 1998;17:171-175. doi:10.7863/jum.1998.17.3.171

185. Rahemtullah A, Leiberman E, Benson C, Norton ME. Outcome of pregnancy after prenatal diagnosis of umbilical vein varix. J Ultrasound Med. 2001;20:135-139. doi:10.7863/jum.2001.20. 2.135

186. Lee SW, Kim MY, Kim JE, Chung JH, Lee HJ, Yoon JY. Clinical characteristics and outcomes of antenatal fetal intra-abdominal umbilical vein varix detection. Obstet Gynecol Sci. 2014;57 (3):181-186. PMID 24883288. doi:10.5468/ogs.2014.57.3.181

187. TRöbs RB, Teig N, Neid M, Gernaianu G, Kozlowski P. Pseudotumrous enlargement of the umbilical cord owing to an intra-amniotic varicosity associated with thrombocytopenia. $J$ Pediatr Surg. 2012;47(9):1760-1762. PMID 22974620. doi:10.1016/j.pedsurg.2012.06.018

188. Batton DG, Amanullah A, Comstock C. Fetal schistocytic hemolytic anemia and umbilical vein varix. J Pediatr Hematol Oncol. 2000;22(3):259-261. doi:10.1097/00043426-200005000-00013

189. Weissman-Brenner A, Simchen MJ, Moran O, Kassif E, Achiron R, Zalel Y. Isolated fetal umbilical vein varix - prenatal sonographic diagnosis and suggested management. Prenat Diagn. 2009;29(3):229-233. PMID 19177454. doi:10.1002/pd.2219

190. Babay ZA, Lange IR, Elliott PD, Hwang WS. Varix dilatation of the umbilical vein and review of the literature. Fetal Diagn Ther. 1996;11(3):221-223. doi:10.1159/000264306

191. Vandevijver N, Hermans RH, Schrander-Stumpel CC, Arenda JW, Peeters LL, Moerman PL. Aneurysm of the umbilical vein: case report and review of the literature. Eur J Obstet Gynecol Reprod Biol. 2001;89(1):85-87. PMID 10733030. doi:10.1016/s0301-2115(99)00167-0

192. Panda B, Stiller R, Iruretagoyena I, Levi A. Prenatal diagnosis of an umbilical vein aneurysm. Conn Med. 2009;3(8):465-467. PMID 19777980.
193. Akar M, Dilli D, Sandal G, Öncel MY, Erdeve Ö, Dilmen U. Prenatally diagnosed umbilical vein aneurysm with good prognosis. J Clin Ultrasound. 2012;40(6):368-369. PMID 22565416. doi:10.1002/jcu.21938

194. Shipp TD, Bromley B, Benacerraf B. Sonographically detected abnormalities of the umbilical cord. Int $J$ Gynaecol Obstet. 1995;48(2):179-185. PMID 7789592. doi:10.1016/0020-7292 (94)02297-c

195. Sepulveda A, Corral E, Kottman C, Vasquez P, Monckeberg MJ, Monckeberg MJ. Umbilical artery aneurysm: prenatal identification on three fetuses with trisomy 18. Ultrasound Obstet Gynecol. 2003;21(3):292-296. PMID 12666226. doi:10.1002/uog.69

196. Berg C, Geipel A, Germer U, Gloeckner-Hoffman K, Gembruch U. Prenatal diagnosis of umbilical cord aneurysm in a fetus with trisomy 18. Ultrasound Obstet Gynecol. 2001;17 (1):79-81. PMID 12244663. doi:10.1046/j.1469-0705.2001.00 313.x

197. Siddiqi TA, Bendon R, Schultz DM, Miodovnik M. Umbilical artery aneurysm: prenatal diagnosis and management. Obstet Gynecol. 1992;80(3Pt2):530-533. PMID 1495730.

198. Shen O, Reinus CM, Baranov A, Rabinowitz RR. Prenatal diagnosis of umbilical artery aneurysm: a potentially lethal anomaly. J Ultrasound Med. 2007;26(2):251-253. doi:10.7863/jum.2007. 26.2.251

199. Weber MA, Sau A, Maxwell DJ, Mounter NA, Lucas SB, Sebire NJ. Third trimester intrauterine fetal death caused by arterial aneurysm of the umbilical cord. Ped Dev Pathol. 2007;10(4):305-308. PMID 17638427. doi:10.2350/06-070136.1

200. Sentilhes L, Vivet-Lefébure A, Patrier S, et al. Umbilical artery aneurysm in a severe growth-restricted fetus with normal karyotype. Prenat Diag. 2007;27(11):1059-1061. PMID 176213 86. doi:10.1002/pd.1817

201. Doehrman P, Derksen B, Perlow JH, Clewell WH, Fineberg HJ. Umbilical artery aneurysm: a case report, literature review, and management recommendations. Obstet Gynecol Surv. 2014;69 (3):159-163. PMID 25102347. doi:10.1097/OGX.0000000000 000051

202. Hill AJ, String TH, Elliott JP, Perlow JH. Umbilical artery aneurysm. Obstet Gynecol. 2010;116(Suppl 2):559-562. PMID 20664454. doi:10.1097/AOG.Ob013e3181e7d280

203. Olog A, Thomas JT, Petersen S, Cattanach S, Lourie R, Gardner G. Large umbilical artery aneurysm with a live healthy baby delivered at 31 weeks. Fetal Diagn Ther. 2011;29 (4):331-333. PMID 21212655. doi:10.1159/000322960

204. Vyas NM, Manjeera L, Rai SD. Prenatal diagnosis of umbilical artery aneurysm with good fetal outcome and review of the literature. J Clin Diagn Res. 2016;10(1):QD1-QD03. PMID 26894129.

205. Matsuki R, Nakago S, Kato H, Shibata T, Kotera T, Kotsuji F. Management strategy of umbilical artery aneurysm complicated by cardiac anomaly: case study and literature review. J Matern Fetal Neonatal Med. 2017;30(15):1809-1812. PMID 27580274. doi:10.1080/14767058.2016.1226796

206. Peng HQ, Levitin-Smith M, Rochelson B, Kahn E. Umbilical cord stricture and overcoiling are common causes of fetal demise. Pediatr Dev Pathol. 2006;9(1):14-19. PMID 16808633. doi:10.2350/05-05-0052.2

207. French AE, Gregg VH, Newberry Y, Parsons T. Umbilical cord stricture: a cause of recurrent fetal death. Obstet Gynecol. 2005;105(5 Pt 2):123-129. PMID 15863594. doi:10.1097/01. AOG.0000159041.55845.f7

208. Sun Y, Arbuckle S, Hocking G, Billson V. Umbilical cord stricture and intrauterine fetal death. Pediatr Pathol Lab Med. 1995;15(5):723-732. PMID: 8597859. doi:10.3109/1551381 9509027008 
209. Hallak M, Pryde PG, Quresji F, Johnson MP, Jauques SM, Evans MI. Constriction of the umbilical cord leading to fetal death. A report of three cases. J Reprod Med. 1994;39 (7):561-565. PMID 7966052.

210. Langhe R, Akpan E, Selvamani S, McEntagart N. Umbilical cord stricture causing intrauterine death. Ir Med J. 2020;113(4):62. PMID 32268055

211. Robertson RD, Rubinstein LM, Wolfson WL, Lebherz TB, Blanchard JB, Crandall BF. Constriction of the umbilical cord as a cause of fetal demise following midtrimester amniocentesis. J Reprod Med. 1981;26(6):325-327. PMID 7252953.

212. Askenazy M, Borenstein R, Katz Z, Segal M. Constriction of the umbilical cord by amniotic band after midtrimester amniocentesis. Acta Obstet Gynecol. 1982;61(1):89-91. PMID 7090754. doi:10.31109/00016348209156959

213. Hadar A, Hallak M. Single umbilical artery and umbilical cord torsion leading to fetal death. A case report. J Reprod Med. 2003;48(9):739-740. PMID 14562642.

214. Ben-Arie A, Weissman A, Steinberg Y, Levy R, Hagay Z. Oligohydramnios, intrauterine growth retardation and fetal death due to umbilical cord torsion. Arch Gynecol Obstet. 1995;256 (3):159-161. PMID 7574909. doi:10.1007/BF01314645

215. Collins JC, Muller RJ, Collins CL. Prenatal observation of umbilical cord abnormalities: a triple knot and torsion of the umbilical cord. Am J Obstet Gynecol. 1993;169(1):102-104. PMID 8333430. doi:10.1016/0002-9378(93)90139-a

216. Collins JH. Prenatal observation of umbilical cord torsion with subsequent premature labor and delivery of a 31- week infant with mild nonimmune hydrops. Am J Obstet Gynecol. 1995;172 (3):1048-1049. PMID 7892849. doi:10.1016/0002-9378(95) 90045-4

217. Bakotic MW, Bord T, Poppiti R, Pflueger S. Recurrent umbilical cord torsion leading to fetal death in subsequent pregnancies: a case report and review of the literature. Arch Pathol Lab Med. 2000;124(9):1352-1355. PMID 10975937. doi:10.5858/2000124-1352

218. Schiesser M, Lapaire O, Holtzgreve W, Tercanli S. Umbilical cord edema associated with patent urachus. Ultrasound Obstet Gynecol. 2003;22(6):646-647. PMID 14689541. doi:10.1002/ uog.924

219. Osawa K, Ito M, Sugiyama M, Kanamori Y, Hashizume K, Marumo G. Vesicoallantoic cyst in the umbilical cord. Fetal Diagn Ther. 2003;18:87-90. doi:10.1159/000068067

220. Campo LR, Cornudella RS, Alderete FG, et al. Prenatal diagnosis of umbilical cord cyst; Clinical significance and prognosis Taiwan J Obstet Gynecol. 2017;56:622-627. doi:10.1016/j. tjog.2017.08.008

221. Emura T, Kanamori Y, Ito M, et al. Omphalocele associated with large multilobar umbilical cord pseudocyst. Pediatr Surg Int. 2004;20 (8):636-639. PMID 15449087. doi:10.1007/s00383-004-1247-y

222. Ross JA, Jurkovic D, Zosmer N, Jauniaux E, Hacket E, Nicolaides KH. Umbilical cord cysts in early pregnancy. Obstet Gynecol. 1997;89(3):442-445. PMID 9052602. doi:10.1016/ S0029-7844(96)00526-1

223. Sepulveda W, Leible S, Ulloa A, Ivankovic C, Schnapp C. Clinical significance of first trimester umbilical cord cysts. $J$ Ultrasound Med. 1999;18(2):95-99. PMID 10206815 doi:10.7863/jum.1999.18.2.95

224. Ghezzi F, Raio L, Di Naro E, Franchi M, Cromi A, Dürig P. Single and multiple umbilical cord cysts in early gestation: two different entities. Ultrasound Obstet Gynecol. 2003;21(3): 215-219. doi: 10.1002/uog.68

225. Gilboa Y, Kivilevitch Z, Katzora E, et al. Outcome of fetuses with umbilical cords cysts diagnosed during nuchal translucency examination. J Ultrasound Med. 2011;30(11):1547-1551. doi:10. 7863/jum.2011.30.11.1547
226. Smith GN, Walker M, Johnson S, Ash K. The sonographic finding of persistent umbilical cord cystic masses is associated with lethal aneuploidy and/or congenital anomalies. Prenat Diagn. 1996;16 (12):1141-1147. doi:10.1002/(SICI)1097-0223(199612)16:12<11 41::AID-PD2>3.0.CO;2-4

227. Zangen R, Boldes R, Yaffe H, Schwed P, Weiner Z. Umbilical cord cysts in the second and third trimesters: significance and prenatal approach. Ultrasound Obstet Gynecol. 2010;36 (3):296-301. PMID 20131340. doi:10.1002/uog.7576

228. Gualandri G, Rivasi F, Santunione AL, Silingardi E. Spontaneous umbilical cord hematoma; an unusual cause of fetal mortality: a report of 3 cases and review of the literature. Am J Forensic Med Pathol. 2008;29(2):185-190. PMID 18520492. doi:10.1097/ PAF.Ob013318174e1

229. Abraham A, Rathore S, Gupta M, Benjamin SJ. Umbilical cord haematoma casing stillbirth - a case report. J Clin Diagn Res. 2015;9(12):QD01-QD02. PMID 26816950. doi:10.7860/JCDR/ 2015/16106.6856

230. Summerville JW, Powar JS, Ueland K. Umbilical cord hematoma resulting in intrauterine fetal demise. A case report. $J$ Reprod Med. 1987;32(3):213-216. PMID 3572905.

231. Romero R, Chervenak FA, Coustan D, Berkowitz RL, Hobbins JC. Antenatal sonographic diagnosis of umbilical cord laceration. Am J Obstet Gynecol. 1982;143(6):719-720. PMID 7091248. doi:10.1016/0002-9378(82)90123-5.

232. Morin LR, Bonan J, Vendrolini G, Bourgeois C. Sonography of umbilical cord hematoma following genetic amniocentesis. Acta Obstet Gynecol Scand. 1987;66(7):669-670. PMID 3326394. doi:10.3109/00016348709022080

233. Zacut H, Lotan M, Achiron R. Umbilical cord damage and placental abruption during amniocentesis. Acta Obstet Gynecol Scand. 1984;63(3):279-281. PMID 6730948. doi:10.3109/000 16348409155516

234. Kirshen EJ, Benirschke K. Fetal exsanguination after amniocentesis. Obstet Gynecol. 1973;42(4):615-616. PMID 4742667. doi:10.1097/00006250-197310000-00024

235. Keckstein G, Tshürtz S, Scheinder V, Hütter W, Terinde R, Jonatha WD. Umbilical cord hematoma as a complication of intrauterine intravascular blood transfusion. Prenat Diagn. 1990;10(1):59-65. PMID 2107537. doi:10.1002/pd.1970100109

236. Feldberg D, Ben-David M, Dicker D, Samuel N, Goldman J. Hematoma of the umbilical cord with acute antepartum fetal distress. J Reprod Med. 1986;31(1):65-66. PMID 3950887.

237. Sepulveda W, Wong AE, Gonzalez R, Vasquez P, Gutierrez J. Fetal death due to umbilical cord hematoma: a rare complication of umbilical cord cyst. J Matern Fetal Neonatal Med. 2005;18 (6):387-390. PMID 16390804. doi:10.1080/14767050500277602

238. Sánchez-Códez MI, Lubián-Gutiérrez M, Méndez-Abad P. Umbilical cord hematoma. Fetal Pediatr Pathol. 2019;38(4):359-360. PMID 30947594. doi:10.1080/15513815.2019.1584656

239. Naidu M, Nama V, Karoshi M, Kakumani V, Worth R. Umbilical cord rupture: a case report and review of the literature. Int J Fertil Womens Med. 2007;52(2-3):107-110. PMID 18320869.

240. Petrikovsky BM, Cooperman B, Kahn E, Pestrak H. Prenatal diagnosis of non-iatrogenic hematoma of the umbilical cord. $J$ Clin Ultrasound. 1996;24(1):37-39. PMID 8655666. doi:10.1002/(SICI)1097-0096(19960)24:1<37::AID-JCU ><37:: AID-JCU>3.0CO;2-M

241. Chou ZY, Chen YR, Wu CF, et al. Spontaneous umbilical hematoma diagnosed antenatally with ultrasonography. Acta Obstet Gynecol Scand. 2003;82:1056-1057. doi:10.1034/j.1600-0412. 2003.00087.x

242. Brown R, Nicolaides K. Umbilical cord hematoma associated with an umbilical cord cyst and fetal death at 28 weeks of gestation. J Ultrasound Med. 2000;19(3):223-225. doi:10.7863/ jum.2000.19.3.223 
243. Curtin WM, Maines JL, DeAngeleis CT, Condon NA, Ural SH, Millington KA. Hemorrhage from umbilical cord ulceration identified on real-times ultrasound in a fetus with duodenal atresia. Case Report Obstet Gynecol. 2019;2019:2680170. doi:10.1155/ 2019/2680170

244. Angelico G, Spadola A, Ieni A, et al. Hemangioma of umbilical cord with associated amniotic inclusion cyst: two uncommon entities occurring simultaneously. Pathologica. 2019;111:13-17. doi:10.32074/1591-951X-26-17

245. Kamitomo M, Sueyoshi K, Matsukita S, Matsuda Y, Hatae M, Ikenoe T. Hemangioma of the umbilical cord: stenotic change of the umbilical vessels. Fetal Diagn Ther. 1999;14(6):328-331. PMID 10640869. doi:10.1159/000020951

246. Seifer D, Ferguson JE, Behrens CM, Zemel S, Stevenson DK, Rose JC. Nonimmune hydrops fetalis in association with hemangioma of the umbilical cord. Obstet Gynecol. 1985;66 (2):283-286. PMID 3895076.

247. Drombrowski MP, Budev H, Wolfe HM, Sokol RJ, Perrin E. Fetal hemorrhage from umbilical cord hemangioma. Obstet Gynecol. 1987;70(3 Pt 2):439-442. PMID 3627598.

248. Smulian JC, Sarno AP, Rochon ML, Loven VA. The natural history of an umbilical cord hemangioma. J Clin Ultrasound. 2016;44(7):455-458. PMID 26899634. doi:10.1002/jcu.22346.

249. Vougiouklakis T, Mitselou A, Zikopoulos K, Dallas P, Charalabopulous K. Ruptured hemangioma of the umbilical cord and intrauterine fetal death, with review data. Pathol Res Pract. 2006;202(7):537-540. PMID 16684589. doi:10.1016/j. prp.2006.02.008

250. Jacques SM, Qureshi F. Hemangioma of the umbilical cord with amniotic epithelial inclusion cyst. Fetal Pediatr Pathol. 2013;32 (3):235-239. PMID 23017112. doi:10.3109/15513815.2012. 721478

251. Matsuda S, Sato Y, Marutsuka K, et al. Hemangioma of the umbilical cord with pseudocyst. Fetal Pediatr Pathol. 2011;30 (1):16-21. PMID 21204661. doi:10.3109/15513811003796920

252. Resta RG, Luthy DA, Mahony BS. Umbilical cord hemangioma associated with extremely high alpha-fetoprotein levels. Obstet Gynecol. 1988;72(3 Pt 2):488-491. PMID 2457194.

253. Miller KA, Gauderer MW. Hemangioma of the umbilical cord mimicking an omphalocele. J Pediatr Surg. 1997;32(6):810-812. PMID 9200074. doi:10.1016/s0022-3468(97)90625-4

254. Pollack MS, Bound NM. Hemangioma of the umbilical cord. Sonographic appearance. J Ultrasound Med. 1989;8(3):163-166. doi:10.7863/jum/1989.8.3.163

255. Mishriki YY, Vanyselbaum Y, Epstein H, Blanc W. Hemangioma of the umbilical cord. Pediatr Pathol. 1987;7(1):43-49. doi:10.1080/15513818709177113

256. Ghidini A, Romero R, Eisen RN, Smith GJ, Hobbins JC. Umbilical cord hemangioma. Prenatal identification and review of the literature. J Ultrasound Med. 1990;9(5):297-300. PMID 2188011. doi:10.7863/jum.1990.9.5.297

257. Schwickert A, Seeger KH, Rancourt RC, Henrich W. Prenatally detected umbilical cord tumor as a sign of diffuse neonatal hemangiomas. J Clin Ultrasound. 2019;47(6):366-368. PMID 30673136. doi:10.1002/jcu.22689

258. Sahinoglu Z, Uludogan M, Deilkara NM. Prenatal sonographic diagnosis of Klippel-Trenaunay-Weber syndrome associated with umbilical cord hemangioma. Am J Perinatol. 2003;20(1):1-6. PMID 12638074. doi:10.1055/s-2003-37950

259. Yu D, Sun L, Chen T. Prenatal ultrasound diagnosis of Klippel-Trenaunay-Weber syndrome associated with umbilical cord hemangioma. J Clin Ultrasound. 2020;49(3):254-256. PMID 33210306. doi:10.1002/jc22896.

260. Göksever H, Celilogu M, Küpelioglu A. Angiomyxoma: a rare tumor of the umbilical cord. J Turk Ger Gynecol Assoc. 2010;11 (1):58-60. PMID 24691896.
261. Jauniaux E, Moscoso G, Chitty L, Gibb D, Driver M, Cambell S. An angiomyxoma involving the whole length of the umbilical cord. Prenatal diagnosis by ultrasonography. J Ultrasound Med. 1990;9 (7):419-422. PMID 2197425. doi:10.7863/jum.1990.9.7.419

262. Yavner DL, Redile RW. Angiomyxoma of the umbilical cord with massive cystic degeneration of Wharton's jelly. Arch Pathol. 1989;113(8):935-937. PMID 2547350.

263. Cheng HP, Hsu CY, Chen CP, Su TH. Angiomyxoma of the umbilical cord. Taiwan J Obstet Gynecol. 2006;45(4):360-362. PMID 17175501. doi:10.1016/S1028-4559(09)60262-X

264. Wilson RD, Magee JF, Sorensen PH, Johnson A. In utero decompression of umbilical cord angiomyxoma followed by vaginal delivery. Am J Obstet Gynecol. 1994;171(5):1383-1385. PMID 7977553. doi:10.1016/0002-937(94)90167-8

265. Gramellini D, Pedrazzoli G, Sacchini C, Montalto M, Pianelli G. Color Doppler ultrasound in prenatal diagnosis of umbilical cord angiomyxoma. Case Report. Clin Exp Obstet Gynecol. 1993;20 (4):241-244.

266. Tennstedt C, Chaoul R, Bollman R, Dietel M. Angiomyxoma of the umbilical cord in one twin with cystic degeneration of Wharton's jelly. A case report. Pathol Res Pract. 1998;194 (1):55-58. PMID 9542748. doi:10.1016/SO344-0344(98)80012.5

267. Zhang L, Hunag S, Li J, et al. A case of umbilical cord angiomyxoma with massive arteriovenous shunts diagnosed with HDlive Flow. J Med Ultrason (2001). 2021;48(1):109-110. doi:10.1007/s10396-020-01063-1

268. Adams KV, Berniieh A, Morris RW, Saad AG. Umbilical cord teratomas associated with congenital malformations. Arch Pathol Lab Med. 2019;144(2):156-159. PMID 31644321. doi:10.5858/ arpa.2019-0161-RA.

269. Diwakar RK, Dwivedi MK. Benign neoplasm of umbilical cord: sonographic diagnosis and short literature review. Arch Radiol. 2019;2(2):24-27.

270. Satgé DCL, Laumond MA, Desfrages F, Chenard MPR. An umbilical cord teratoma in a 17 -week-old fetus. Prenat Diagn. 2001;21(4):284-288. PMID 11288118. doi:10.1002/pd.47

271. Bakhru S, Jmalpuri V, Koneti NR. Diagnosis and management of congenital umbilical arteriovenous malformation. Cardiol Young. 2020;31:1-3. PMID33261691. doi:10.1017/S1047951120004138

272. Boglione MM, D'Alessandro P, Reusman A, Rubio M, Lipsich J, Goldsmith G. Umbilical arteriovenous malformation in a healthy neonate with umbilical hernia. J Neonat Surg. 2013;2(3):35. doi:10.47338/jns.v2.47

273. Meyer M, Barsness KA. Umbilical arteriovenous malformation: a case report and literature review. Pediatr Surg Int. 2013;29 (8):851-853. PMID 23474574. doi:10.1007/s00383-013-3297-5

274. Gregorio-Hernández R, Sanz-López E, Aguado-Del Hoyo A, Manrigue-Martín G, De Agustín JC, Sánchez-Luna M. A rare complex case of congenital umbilical arteriovenous malformation and review of the literature. Am J Perinatol Rep. 2016;6(2):e216e221. PMID 27294008. doi:10.1055/s-0036-1584239

275. Shinata M, Kanehiro H, Shinkawa T, et al. A neonate with umbilical arteriovenous malformation showing hemorrhagic shock massive umbilical hemorrhage. Am J Perinatol. 2009;26 (8):583-586. PMID 19399703. doi:10.1055/s-0029-1220778

276. Suzui I, Masuyama H, Hirano Y, Nishida T, Hayata K, Hiramatsu Y. Prenatal diagnosis of umbilical arteriovenous malformation. J Matern Fetal Neonatal Med. 2017;30(1):85-87. PMID 26952649. doi:10.3109/14767058.2016.1163542

277. Richards DS, Lutfi E, Mullins D, Sandler DL, Raynor BD. Prenatal diagnosis of fetal disseminated intravascular coagulation associated with umbilical cord arteriovenous malformation. Obstet Gynecol. 1995;85(5 Pt 2):860-862. PMID 7724138.

278. Baylis MS, Jones RY, Hughes M. Angiomyxoma of the umbilical cord detected antenatally by ultrasound. J Obstet Gynecol. 1984;4:243-244. 
279. Mei-Dan E, Glanc P, Hui D, Barrett J. Spontaneous resolution of an umbilical cord arteriovenous fistula. Case Rep Perinat Med. 2014;4(1):25-27. doi:10.1515/crpm-2014-0013

280. Pellerito J, Bromley B, Allison S, et al. AIUM-ACR-ACOGSMFM-SRU practice parameter for the performance of standard diagnostic obstetrical ultrasound examinations. J Ultrasound Med. 2018;37:E13-E24. doi:10.1002/jum.14831

281. Salomon LJ, Alfirevic Z, Berghella V, et al.; on behalf of the ISUOG Clinical Standards Committee. Practice guidelines for performance of the routine mid-trimester fetal ultrasound scan. Ultrasound Obstet Gynecol. 2011;37(1):116-126. doi:10.1002/uog.8831.
282. Kumar I, Verma A, Jain M, Shuka RC. Structured evaluation and reporting in imaging of placenta and umbilical cord. Acta Radiol. 2020;61(5):685-704. doi:10.1177/0284185119875644

283. NASA. Ed White, the first American to perform extravehicular activity, outside of Gemini IV; 1965. Available from: https://en.wikipedia.org/wiki/Gemini_4\#/media/File:Ed_ White_First_American_Spacewalker_-_GPN-2000-001180. jpg. Accessed October 1, 2021;

\section{Publish your work in this journal}

The International Journal of Women's Health is an international, peerreviewed open-access journal publishing original research, reports, editorials, reviews and commentaries on all aspects of women's healthcare including gynecology, obstetrics, and breast cancer. The manuscript management system is completely online and includes a very quick and fair peer-review system, which is all easy to use. Visit http://www.dovepress.com/testimonials.php to read real quotes from published authors. 